\title{
Algorithm-Based Intraday Trading Strategies and their Market Impact
}

\section{BACHELOR THESIS}

for the attainment of the academic degree

\section{Bachelor of Arts (B.A.)}

at the

\section{Hochschule für Technik, Wirtschaft und Kultur Leipzig}

Supervising Professor:

Prof. Dr. Uwe Vielmeyer

Second supervising professor:

Prof. Dr. Andreas Piel

By:

Student Number:

Study Program:

Year of Enrolment:

Address:
Müller, Luisa

69517

International Management (IMB)

2017 


\begin{abstract}
The activity of algorithmic trading is increasing steadily across capital markets due to technological developments. This thesis analyses the common algorithmic intraday trading strategies of momentum, mean reversion, and statistical arbitrage. Conclusions were drawn from a literature review of prior and current research. Algorithmic arbitrage was found to be the most profitable of the three evaluated strategies, because it typically takes place in high frequency trading. Furthermore, this thesis analyses the impact of algorithmic trading on market liquidity and volatility. While the literature mainly agrees that algorithmic trading has a positive effect on liquidity, its impact on volatility is subject to discussion. Algorithmic and high-frequency trading carry risks that will likely lead to new future regulations.
\end{abstract}




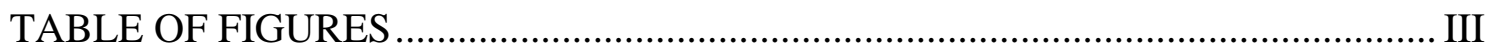

TABLE OF ABBREVIATIONS …….............................................................

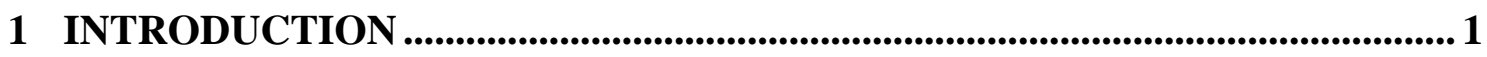

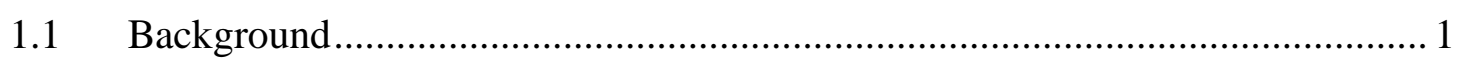

1.2 Problem description and goal of the research.............................................. 2

1.3 Structure of the thesis and research questions ............................................... 3

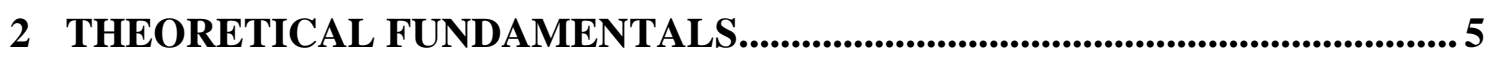

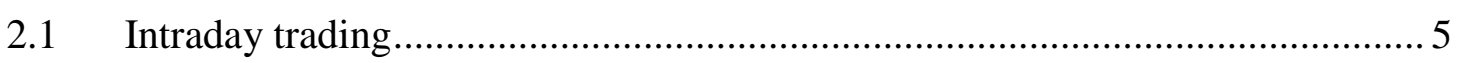

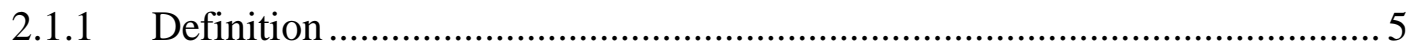

2.1.2 Characteristics of intraday trading markets .............................................. 5

2.1.3 Financial instruments of intraday trading ............................................. 6

2.1.4 Goals and profit chances of individual intraday traders ........................... 7

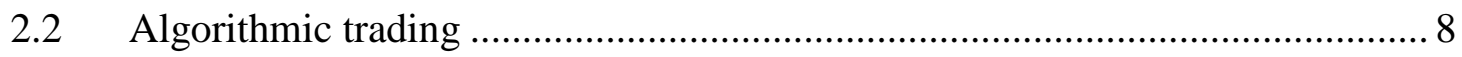

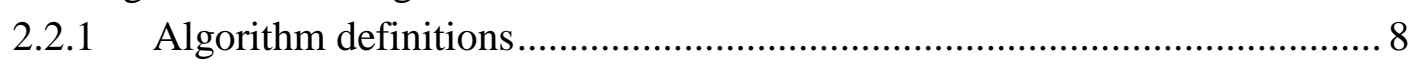

2.2.2 Algorithmic trading definitions ......................................................... 9

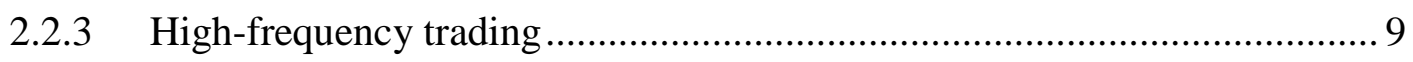

2.2.4 Characteristics of algorithmic trading and high-frequency trading ........... 10

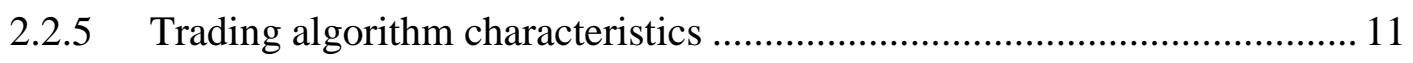

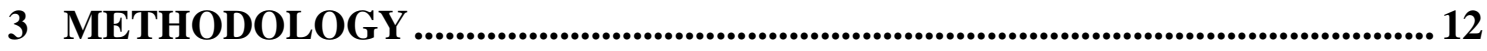

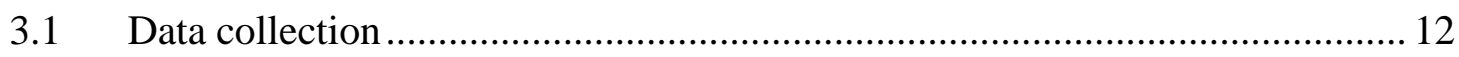

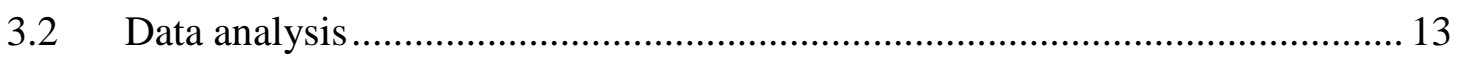

\section{ALGORITHM-BASED INTRADAY TRADING STRATEGIES AND}

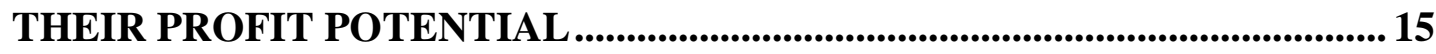

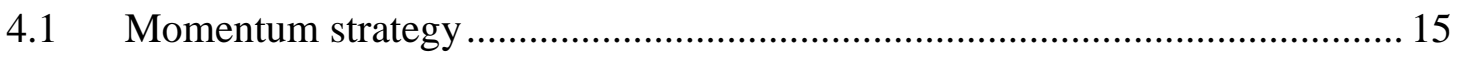

4.1.1 Definition and basic principle of the strategy ........................................ 15

4.1.2 Underlying theories of the momentum strategy ..................................... 15

4.1.3 Selected studies of an algorithmic intraday momentum strategy .............. 18

4.1.3.1 Study A - Schulmeister (2009) ..................................................... 19

4.1.3.2 Study B - Christensen, Turner and Godsill (2020)............................ 21

4.1.3.3 Study C - Herberger, Horn and Oehler (2020) ................................ 22

4.1.3.4 Comparison of the selected studies ............................................... 23

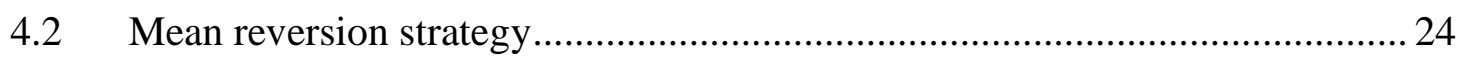

4.2.1 Definition and basic principle of the strategy ......................................... 24

4.2.2 Underlying theories of the mean reversion strategy ................................ 24

4.2.3 Relation of mean reversion and momentum ........................................... 25

4.2.4 Selected studies of an algorithmic intraday mean reversion strategy ........ 26

4.2.4.1 Study A - Schulmeister (2009) ................................................... 26 
4.2.4.2 Study B - Wiśniewska (2014) ...................................................... 27

4.2.4.3 Study C - Herberger, Horn and Oehler (2020) ............................... 28

4.2.4.4 Comparison of the selected studies .................................................. 29

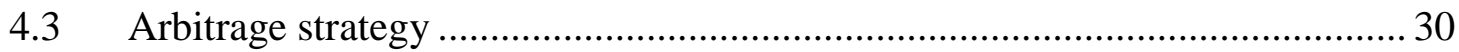

4.3.1 Definition and basic principle of the strategy ......................................... 30

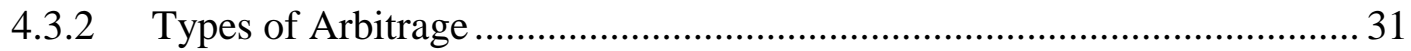

4.3.3 Underlying theories of the arbitrage strategy ........................................ 32

4.3.4 Selected studies of an algorithmic intraday statistical arbitrage strategy .. 32

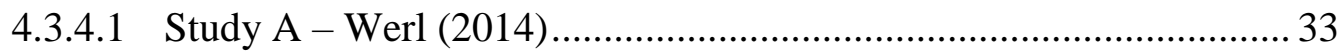

4.3.4.2 Study B - Stübinger and Schneider (2017) ....................................... 34

4.3.4.3 Study C - Stübinger and Schneider (2019) ....................................... 35

4.3.4.4 Study D - Leung and Lee (2020) ...................................................... 35

4.3.4.5 Comparisons of the selected studies ................................................ 37

4.4 Further trading algorithms and strategy components ..................................... 37

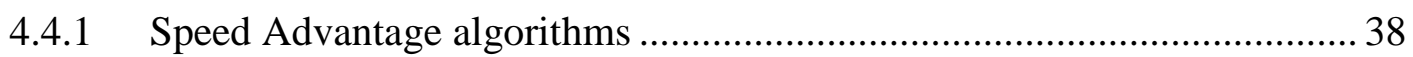

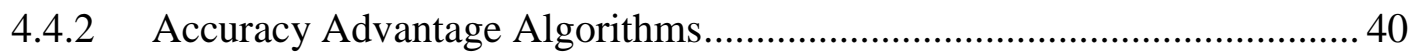

5 IMPACT OF ALGORITHMIC TRADING ON MARKET LIQUIDITY

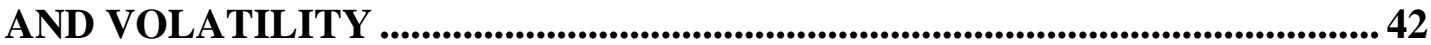

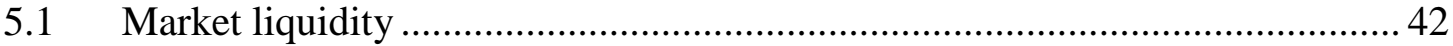

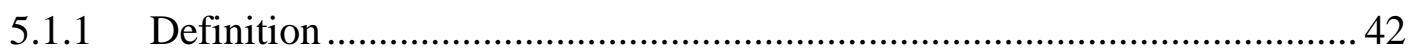

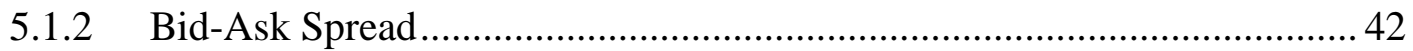

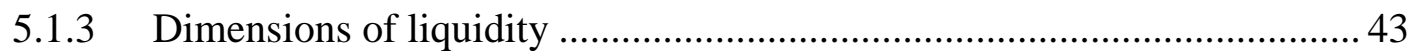

5.1.4 The impact of algorithmic trading on market liquidity............................ 43

5.1.4.1 Hendershott, Jones and Menkveld (2011)........................................ 43

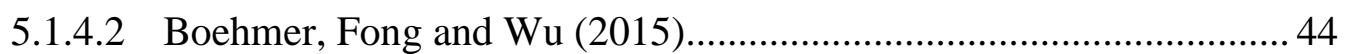

5.1.4.3 Broussard, Nikiforov and Osmekhin (2020) ..................................... 45

5.1.4.4 Golub, Glattfelder and Olsen (2017) - The Alpha Engine ................. 46

5.1.4.5 Statements by public institutions ................................................... 46

5.1.4.6 Comparison of the selected studies and further literature................. 47

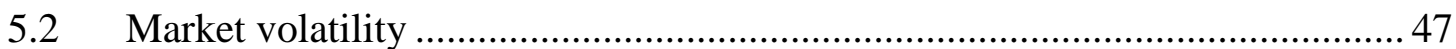

5.2.1 Definition and characteristics of volatility ........................................... 47

5.2.2 The impact of algorithmic trading on market volatility ............................ 48

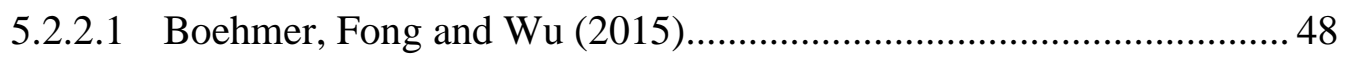

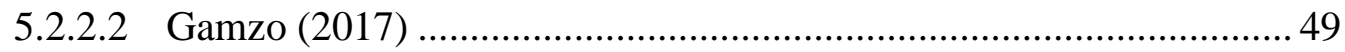

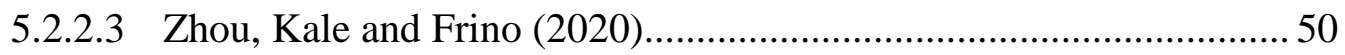

5.2.2.4 Statements of public institutions ........................................................ 51

5.2.2.5 Comparison of the selected studies and further literature ................. 52

6 CONCLUSION AND FUTURE DEVELOPMENTS OF ALGORITHMIC TRADING .................................................................................................................5 53

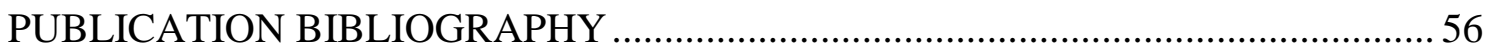

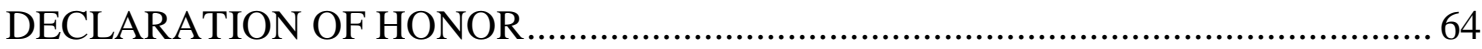


Figure 1: Signal generation rules 1-3 following a momentum strategy ....................... 20

Figure 2: Hidden Markov Model (HMM) applied to trading ...................................... 22

Figure 3: Signal generation rules 4-6 following a mean reversion strategy ................... 27 
Table of Abbreviations

\begin{tabular}{|c|c|}
\hline ADF & Augmented Dickey-Fuller Test \\
\hline AI & Artificial Intelligence \\
\hline $\mathrm{AMH}$ & Adaptive Market Hypothesis \\
\hline APT & Arbitrage Pricing Theory \\
\hline AT & Algorithmic Trading \\
\hline \multirow[t]{2}{*}{ Bafin } & Financial Supervisory Authority/ \\
\hline & Bundesanstalt für Finanzdienstleistungsaufsicht \\
\hline CAPM & Capital Asset Pricing Model \\
\hline CFD & Contract for Difference \\
\hline CNY & Chinese Yuan \\
\hline Ed./Eds. & Editor(s) \\
\hline EMH & Efficient Market Hypothesis \\
\hline et al. & et alii \\
\hline ETF & Exchange-traded fund \\
\hline EUR & Euro \\
\hline FOREX & Foreign Exchange \\
\hline HFT & High-frequeny trading \\
\hline HKD & Hongkong Dollar \\
\hline HMM & Hidden Markov Model \\
\hline JPY & Japanese Yen \\
\hline KPI & Key performance indicator \\
\hline KRW & South Korean Won \\
\hline MA & Moving Average \\
\hline MCMC & Markov Chain Monte Carlo \\
\hline N.d. & No date \\
\hline No. & Number \\
\hline $\mathrm{OU}$ & Ornstein-Uhlenbeck \\
\hline P./pp. & Page(s) \\
\hline PLR & Piecewise linear regression \\
\hline RL & Reinforcement Learning \\
\hline SG & Signal Generation \\
\hline TWAP & Time Weighted Average Price \\
\hline TWD & New Taiwan Dollar \\
\hline US & United States \\
\hline USD & US-Dollar \\
\hline Vol. & Volume \\
\hline VWAP & Volume Weighted Average Price \\
\hline
\end{tabular}




\subsection{Background}

Automation and artificial intelligence (AI) have developed significantly in recent years due to technological developments. ${ }^{1}$ In businesses, automation can take place in nearly every department - from the classical example of a factory that substitutes workers with machines, to the use of AI for targeted marketing, automated accounting, and even talent acquisition in human resources management. ${ }^{2}$ Of course, this development also affects finance and investment management, as well as the whole capital market. A McKinsey study shows that automation has the potential to fundamentally transform the entire finance sector. This is especially true for investment decisions and trading, where considerable quantities of data arise from market situations and stock fluctuations. Both automation and AI use smart algorithms that are able to process large amounts of qualitative and quantitative data. Today, several types of algorithms are also able to improve themselves through machine learning. Thus, it follows that algorithmic trading will increase in line with technological improvements, since more and more data needs to be analysed in ever-shorter periods of time. ${ }^{3}$

Back in 2006, Gsell began analysing the process of algorithmic trading (AT). Gsell determined that an increasing number of functions in the trading process were being executed automatically. The development started with automated stop-loss systems and order routing systems, followed by other steps in the trading value chain. ${ }^{4}$ As a result, nowadays the entire trading process can take place fully automatically. By 2016, already $80 \%$ of the trades in the foreign exchange (FOREX) market were executed algorithmically. An increase was observable in other markets as well. ${ }^{5}$ AT influenced the trading environment and markets heavily, and thus gained considerable importance for all market participants. For this reason, this thesis analyses different algorithmic trading strategies and related returns on different markets, as well as their market impact.

\footnotetext{
${ }^{1}$ See online: U.S. Securities and Exchange Commission (Ed.) (2020), p. 4.

${ }^{2}$ See online: Uzialko, A. (2019).

${ }^{3}$ See online: Chui, M. et al. (2016).

${ }^{4}$ See online: Gsell, M. (2006), p. 2.

${ }^{5}$ See Bigiotti A., Navarra A. (2019), p.254.
} 


\subsection{Problem description and goal of the research}

The topic of algorithmic intraday trading is widely discussed in a large number of scientific articles and has been the subject of many discussions. Due to the rapid digitalization of data in the past decade, the field of AT has developed steadily. ${ }^{6}$

Most professional literature on the subject investigates either one single trading strategy or focuses on further developing an algorithm that is applicable to multiple strategies. Often, only one market is observed. Furthermore, many books and reports of personal AT success stories dominate the field. The effects on market liquidity ${ }^{7}$ and volatility ${ }^{8}$ have been tested in empirical studies and the development of AT through new technologies ${ }^{9}$ has been observed. In the business world, big investment firms that control sizeable percentages of the world's capital spend large amounts of money on the research and development of AT strategies. This further underlines the relevance of the topic.

Despite extensive research on the topic, however, the literature lacks a holistic review which sums up the status quo of the most common AT strategies and the market impact of AT in one paper. The aim of this thesis therefore is to outline scientific research regarding common AT strategies. Furthermore, studies and scientific findings relating to the general impact of AT on the market are discussed. This part of the literature review focuses mainly on the impact on market liquidity and volatility.

Examples of both mature and current literature are subject to this review and the relationships between ideas and practices are identified. Given the fast-paced environment of trading in conjunction with technology, it is crucial to compile a current and comprehensive review of the literature. Specific research questions are given in the following section.

\footnotetext{
${ }^{6}$ See online: Seth, S. (2020).

${ }^{7}$ See Hendershott, T. et al. (2011a), p 1.

${ }^{8}$ See online: Boehmer et al. (2015), p. 1.

${ }^{9}$ Gomber et al. (2018), p. 2.
} 


\subsection{Structure of the thesis and research questions}

This thesis examines the following overall research question, which arises from the research goal and the large number of existing studies:

What is the market impact of algorithmic intraday trading?

In order to concretize this question the literature review focuses on two sub-questions that are reviewed in detail:

I. What is the profit potential of the common algorithmic trading strategies momentum, mean reversion, and arbitrage?

II. What is the influence of algorithmic trading on the liquidity and volatility of markets?

Based on the research questions the thesis is structured as follows:

After giving the background and explaining the relevance of the topic in the first chapter, the second chapter outlines theoretical fundamentals of intraday trading and AT. Definitions and key characteristics of AT are presented.

The third chapter explains the methodologies used in this thesis, including the data collection and data analysis processes.

In the fourth chapter, the existing literature is reviewed and discussed. It focuses on algorithmic intraday trading strategies and the related trading returns generated. Three strategies are examined in detail, which are momentum, mean reversion and statistical arbitrage. These strategies have been chosen due to their popularity in AT and ongoing discussions and studies about them. Each strategy is explained as well as their underlying capital market theories. Then, studies regarding each strategy are compiled and analysed. The data from each study, the mathematical model behind the algorithm, and the trading returns generated by the AT system, are summarized. The studies focus on different markets and trading assets to give a multifaceted overview. In addition, those studies that focus on the same strategy are compared. 
The fifth chapter outlines the relevance of the topic to the entire marketplace. Impacts of AT on market liquidity and volatility are reviewed in detail. As with the review process in Chapter 4, several studies concerning liquidity and volatility are analysed and the findings are compared with each other.

In Chapter 6, the results of the thesis are finally summarized and deliberated. A brief explanation of the future developments of AT complete the thesis. 
This thesis requires a basic understanding of intraday and algorithmic intraday trading that the following sections will provide. It is favourable to delimit the terms intraday trading and algorithmic trading to ensure a sound understanding of both principles. Furthermore, a general understanding of trading algorithms and their functionality is necessary, what the following sections will explain.

\subsection{Intraday trading}

\subsubsection{Definition}

While the literature of intraday trading is diverse, definitions of the term are similar. The term 'intraday trading' is equivalent to the term 'day trading ${ }^{6} .{ }^{10}$ The prevailing understanding is that day trading is "the activity, often on the internet, of buying and selling shares on the same day, reacting to small changes in prices in order to make a profit: (...)". ${ }^{11}$ Chen adds to the definition that a large volume of trades is typically executed per day. ${ }^{12}$

\subsubsection{Characteristics of intraday trading markets}

Intraday trading cannot be executed on every desired market. Instead, markets must fulfil four criteria to enable investors to trade in between a day. The first characteristic is high liquidity of the market. ${ }^{13}$ Liquidity is defined by Harris as the ability to execute an order with a large volume without causing a significant price change to every desired time. ${ }^{14}$ Another requirement for day trading markets is high volatility. ${ }^{15}$ According the Handbook of International Financial Terms, the term 'volatility' refers to large and rapid price changes of a market or a financial asset. ${ }^{16}$ More generally, volatility is the changeableness of a variable. Daly states that, "(...) the more the variable fluctuates over a period of time, the more volatile the variable is said to be". ${ }^{17}$ Furthermore, low transaction costs and a

\footnotetext{
${ }^{10}$ See online: Admiral Markets (Ed.) (2020); Forex Live (Ed.) (2019).

${ }^{11}$ Combley, R. (2011).

12 See online: Chen, J. (2019).

${ }^{13}$ See Chung, J.M. et al. (2008), p. 240.

${ }^{14}$ See online: Gomolka, J. (2011), p. 5.

${ }^{15}$ See online: Seth, S. (2019).

${ }^{16}$ See Moles, P. (1997).

${ }^{17}$ Daly, K. J. (2011), p. 46-47.
} 
high availability of information should be given due to the high number of trades that are accomplished by traders per day. ${ }^{18}$

\subsubsection{Financial instruments of intraday trading}

These characteristics do not fit every market, so not all available securities are suitable assets for intraday trading. When researching markets that fulfil the criteria listed above, the FOREX market is identified as a highly liquid market. It is considered as a major financial market in the world, with a market capitalization of 6 trillion dollars per day. ${ }^{19}$ Furthermore, it is a 24-hour market unrestricted by business times. The traded assets are currency pairs that represent the exchange rates of two currencies. Due to the high liquidity of the market, the bid-ask spread decreases, which will be further explained in section 5.1.2. This leads to reduced transaction costs. ${ }^{20}$ As foreign exchange rates can be traded, the same is possible with cryptocurrencies. ${ }^{21}$

Other common classes of derivatives that are attractive for day trading are contracts for difference (CFDs), futures contracts and options. CFDs enable traders to bet on price movements of the underlying assets, which can be stocks, indexes or commodities. The trader buys the CFD at a special price and, if this value rises while the trader holds it, he or she receives the difference. On the other side, if the current holding value falls below the contract entering value, they lose the difference. ${ }^{22}$ CFDs do not provide the ownership of the underlying asset, but the benefits and risks of ownership. ${ }^{23}$

In contrast to this, futures are purchasable contracts that determine a special date in the future on which the owner must buy a predetermined quantity of the underlying asset for a predetermined price. In regarding to this arrangement, traders speculate on the direction of prices. The underlying assets are volatile stocks, indexes, interest rates or commodities. Physical delivery of the assets can be included, for instance in agricultural or energy futures. ${ }^{24}$

\footnotetext{
${ }^{18}$ See online: Seth, S. (2019).

${ }^{19}$ See online Charles, D. (2018), p. 8.

${ }^{20}$ See online Charles, D. (2018), p. 8.

${ }^{21}$ See online: Lee, D. et al. (2020), p. 16.

${ }^{22}$ See Lee A. D. et al. (2014), p. 967.

${ }^{23}$ See online: Chen, J. (2020a).

${ }^{24}$ See Leung, T. et al. (2016), p. 282.
} 
Options contracts differ from futures in that they do not oblige the buyer to purchase the underlying asset, but give them the opportunity to buy or sell it. ${ }^{25}$ Trading options are preferred over trading the underlying assets themselves, because they offer lower transaction costs, higher financial leverage, and higher volatility. ${ }^{26}$ In intraday trading, the stock market itself is not preferred, because the risk that large market participants manipulate the market is high. ${ }^{27}$

\subsubsection{Goals and profit chances of individual intraday traders}

The overall goal of day trading is to turn the small intraday price movements of an asset into profit without holding it overnight. Traders purchase an asset and try to sell it for a higher price. Hence, they try to leverage small price increases by purchasing a larger volume of assets. ${ }^{28}$ The principle is simple, but the practice reveals differences in successfully applying these principles. There are several studies referring to the profitability of intraday trading. Barber, Lee, Liu and Odean researched this issue on the Taiwanese market. A study conducted in 2004 showed that less than $20 \%$ of the traders earned a net profit. $^{29}$ Analysing day traders from the United States (US), a study conducted in 2003 showed a similar result, with only $20 \%$ of the sample of traders being profitable. ${ }^{30}$ Research of the Korean stock exchange shows that the average return of day traders yields is $-0.39 \%$, or including transaction fees is $-0.81 \%$. Approximately $43 \%$ of traders gained any abnormal positive returns during the period observation. By contrast, the consistency of these positive returns could not be found and day trading could not be confirmed as profitable in general. ${ }^{31}$ In 2011, Barber et al. found a similar result in another study. Furthermore, they researched that only a small group of day traders, less than one percent of all, are able to predict positive abnormal net returns. ${ }^{32}$ Several years later, in 2017, it was found that the majority of day traders who were active on the Taiwanese day trading market were unprofitable. While evaluating the data relating to day traders from 1995 to 2006 it was observed that the share of profitable day traders remained continuous

\footnotetext{
${ }^{25}$ See online: Chen, J. (2020b).

${ }^{26}$ See Ansi, A. et al. (2009), p. 155.

${ }^{27}$ See online: Charles, D. (2018), p. 8

${ }^{28}$ See online: Charles, D. (2018), p. 2.

${ }^{29}$ See online: Barber, B.M. et al. (2004), p. 21.

${ }^{30}$ See Jordan, D. J. et al. (2003), p. 1.

${ }^{31}$ See Lee, E. et al. (2007), p. 352.

${ }^{32}$ See Barber, B.M. et al. (2011), p. 3, See online: Tracy, P. (n.d.): Abnormal returns mean the difference between the actual and the expected return. Market indexes can be used to calculate the expected return benchmark.
} 
at around 5\%. ${ }^{33}$ Scientific research results stand in stark contrast to the large amount of guides and day trading platforms that predict huge profits and the suitability of day trading for a living. This thesis will further evaluate whether day trading has become more profitable due to automation through algorithms and their higher trading speed in section 4.

\subsection{Algorithmic trading}

\subsubsection{Algorithm definitions}

In terms of the topic of this thesis, it is necessary to understand the basic function of algorithms. An algorithm is defined as "a set of mathematical instructions that must be followed in a fixed order, and that, especially if given to a computer, will help to calculate an answer to a mathematical problem: (...)" ${ }^{34}$ Since the middle of the 20th century, programmed algorithms have gained considerable attention and their economic and scientific influences have increased significantly. ${ }^{35}$ Computers are programmed using algorithms and, in this way, every digital communication is based on them. In the complex field of computers and software, algorithms must be able to process pictures, videos, sounds, and news reports, as well as numbers. The most important functions are those involved in the management of processes and automation. Thus, algorithms handle the correct order in which a process is executed: for example, data transfers and accounting entries. Besides this, they enable automation: one signal triggers the operation of a process. Of course, special programs and appropriate programming languages are needed for the creation of new algorithms or the change of existing ones. Python, Ruby, C, C\#, $\mathrm{C}++$ and Java are among the most common, high-level programming languages. ${ }^{36}$ The manner of algorithmic functioning and the wide variety of algorithms available have a tremendous importance for the following topic of algorithmic trading and, in turn, its influence on the markets. ${ }^{37}$

\footnotetext{
${ }^{33}$ See online: Barber, B.M. et al. (2017), p. 15-16.

${ }^{34}$ See McIntosh, C. (2013).

${ }^{35}$ See Grimm, R. et al. (2017), p. 29-30.

${ }^{36}$ See online: EDUCBA (Ed.) (n.d.).

${ }^{37}$ See Grimm, R. et al. (2017), p. 31-32.
} 


\subsubsection{Algorithmic trading definitions}

Algorithmic trading is the combination of conventional (day) trading and the increase of the use and creation of computer algorithms. Hendershott, Jones and Menkveld (2011) define algorithmic trading commonly as computer algorithms that make particular trading decisions, order submissions, and post-order management, automatically. ${ }^{38} \mathrm{AT}$ is further defined " (...) as a tool for professional traders that may observe market parameters or other information in real-time and automatically generates/carries out trading decisions without human intervention". ${ }^{39}$ Besides this, the European Commission has introduced a definition in its so-called Markets in Financial Instruments Directive. It determines AT as the automatic trading of financial instruments through computer algorithms, where the algorithms define the parameters of the order, such as order initiation, price, quantity and timing of the order execution, as well the post-order management. This process takes place with minimal or no human intervention. ${ }^{40}$ In general, the definitions have in common that the whole trade process runs automatically through algorithms. Frequent market observation and automated order executions can thus be defined as key features of algorithmic trading. ${ }^{41}$ The definition produced by the European Commission is used as the basis for this thesis, because it is the most precise.

\subsubsection{High-frequency trading}

High-frequency trading (HFT) is an important subcategory of algorithmic trading and a clear differentiation between both terms is sometimes difficult. It is a later phenomenon than algorithmic trading since it requires higher technological standards. This form of algorithmic trading is characterized by its speed, because the trading system analyses market indicators that signal an order in milliseconds or seconds, much faster than humans are capable of. ${ }^{42}$ Therefore, the profitability of HFT is reduced when the system reacts with a 300-millisecond delay. ${ }^{43}$ The system can place large numbers of orders within a moment. Again, this process does not involve human intervention. HFT is also characterized by the short time-frame of buying and selling positions, the high daily portfolio order, and the high order-to-trade ratio. Due to its speed, more orders, quotes

\footnotetext{
${ }^{38}$ See Hendershott, T. et al. (2011a), p. 1.

${ }^{39}$ Gomber et al. (2011), p. 14.

${ }^{40}$ See The European Parliament and the Council of the European Union (Ed.) (2014), p. 358-359.

${ }^{41}$ See Gomber et al. (2018), p. 2.

${ }^{42}$ See Gomber et al. (2018), p. 3-4.

${ }^{43}$ See online: Zhou, H. (2017), p. 23.
} 
and order cancellations take place per day than in regular AT. HFT serves to execute trading according to traditional strategies faster and to use more advanced technology to generate more profit in a shorter period. ${ }^{44}$ On the other hand, HFT is held responsible for the so-called 'Flash Crash' in 2010, where an automated trading program caused heavy exchange rate fluctuations in only a few minutes. ${ }^{45}$

\subsubsection{Characteristics of algorithmic trading and high-frequency trading}

AT and HFT have special characteristics that should determine the speed of a trade. To ensure a fast and unobstructed trade, it is necessary to keep latencies as low as possible. Latency here means the loss of time through the transfer of electronic messages, which emerge between order release and processing of the order. This influences the order negatively and can lead to a time-delayed supply of information to the trader. ${ }^{46}$ In order to reduce latencies, high-frequency traders are characterized by their use of co-location, proximity hosting, or high-speed direct access.

Co-location represents the physical proximity of traders or trading firms and the data centre with the servers of a stock exchange. Trading venues are obliged to offer these colocation services on a fair basis. ${ }^{47}$ Co-location provides the advantage of receiving market information and prices earlier. Although this translates into an advantage of nanoseconds, trading firms and individuals pay millions of dollars due to the enormous speed of HFT. ${ }^{48}$ Proximity hosting offers the same advantage, the only difference being that the trader or trading firms do not place their own computer system close to the trading venue's systems, but use computer systems provided by third parties. Furthermore, if traders or trading firms own high-speed direct electronic market access, a transmission of messages in nanoseconds is allowed.

Besides this, bandwidth has a similar importance. This refers to the possible amount of data transferred per second on a connection. The German Federal Financial Supervisory Authority (Bafin) recommends a bandwidth of 10 gigabits per second. ${ }^{49}$

\footnotetext{
${ }^{44}$ See The European Parliament and the Council of the European Union (Ed.) (2014), p. 358-359.

${ }^{45}$ See Kirilenko, A. et al. (2017), p. 968.

${ }^{46}$ See online: Gomolka, J. (2011), p. 93.

${ }^{47}$ See The European Parliament and the Council of the European Union (Ed.) (2014), p. 359.

${ }^{48}$ See online: Binance Academy (Ed.) (n.d.).

${ }^{49}$ See online: BaFin - Bundesanstalt für Finanzdienstleistungsaufsicht (Ed.) (2019).
} 


\subsubsection{Trading algorithm characteristics}

Trading algorithms consist of at least one buying command and at least one selling command to determine the moment a trade should be placed. When the algorithm is simple, as mostly in conventional day trading, values and prices can be determined manually, but in algorithms that are more complex, computer systems are necessary to support the execution. The algorithms should detect the moment when the buying or selling command fits the market situation and promises a potential profit. For every instant of time, it gives a value that is often either true or false and indicates if a trading signal is generated. That is why the algorithms must be designed to run frequently and produce an outcome for every instant of time. ${ }^{50}$

Trading algorithms stand out for some special attributes that include verifiability, consistency, quantifiability, objectivity, and expandability. The first attribute means that the algorithm must be checkable and traceable with the help of back-testing ${ }^{51}$ and simulation. When the testing shows that the algorithm has the potential to generate profits, then it is valid. 'Consistency' means the algorithm and all included commands are executed without human intervention. 'Quantifiability' is the basis for the evaluation of a trading algorithm. To determine profitability, quantitative key performance indicators (KPIs) are calculated with simulations of historical performance so that different trading algorithms can be compared with each other. Another criterion that trading algorithms fulfil is objectivity, because algorithms enact instructions strictly without the influence of emotions. 'Expandability' here refers to the ability of trading algorithms to perform in different markets. Furthermore, the commands are easily changeable, adaptable and expandable..$^{52}$

\footnotetext{
${ }^{50}$ See online: Kersch, M. (2014), p. 87-88.

${ }^{51}$ See online: Gomolka, J.: Algorithmic Trading (2011), p. 268. In addition: Backtesting describes the testing of the algorithmic trading strategy with a simulation on current market data.

52 See online: Kersch, M. (2014), p. 90-91.
} 
In order to answer the research questions, the approach of a systematic literature review framework by Parris and Peachey (2013) is used. Firstly, data adequate to the question was collected. Secondly, this information was analysed and evaluated. ${ }^{53}$ The methods for these steps will be explained in the following sections to ensure confirmability and transparency.

\subsection{Data collection}

A literature review requires a collection of many types and sources of data. For this study, the process of data collection started with a search for appropriate data in the HTWK Online Library. It was searched for keywords and phrases such as 'algorithmic trading', 'algorithmic trading strategies' and 'market impact of algorithmic trading'. Different combinations of keywords were researched, as well for the category 'title' as for 'all fields'. The results pointed to documents in other libraries, for instance Springer Link and Elsevier Science Direct. These libraries, as well as the commonly known databases Social Science Research Network, Research Gate and Google Scholar, were scanned for suitable literature. With the help of the keywords mentioned, these platforms were explored.

During the research process and the reading of related literature, three AT strategies were particularly noticeable: momentum, mean reversion and arbitrage. It was decided to analyse them further. They were chosen for two reasons. Firstly, while there are a number of other strategies besides the three mentioned, the current literature lacks sufficient material that would support a proper review and discussion of them all. Secondly, the rapid technological improvement of algorithms used for trading has reached a threshold where algorithms learn and improve over time. It is therefore impossible to assign new machine-learning algorithms to a single strategy. For these reasons, the keywords in the literature search were extended accordingly and the structure of the thesis was developed.

For each strategy, several studies were explored in order to show the variety of algorithmic trading approaches and return potentials.

${ }^{53}$ See Goldenstein, J. et al. (2018), pp. 75. 
For the investigation of the market impact, the keywords 'market liquidity' and 'volatility' in relation with algorithmic trading were researched. These two market characteristics were identified as crucial subjects to discussion. Accordingly, the structure of the thesis was extended.

Regarding the time frame of the data, it was necessary to include both historical and contemporary studies. For capital market theories, older literature was used in terms of explaining the rationale behind certain trading strategies. In terms of individual studies, results were filtered for more current literature to present the status quo of AT and its market impact.

Finally, all suitable literature that met these criteria was downloaded and exported into an Excel spreadsheet. A duplicate check followed, since some documents are updated versions of prior ones or have been released by several publishers. Then the abstracts were read and searched for the keywords 'intraday' and 'algorithm(ic)' in each document in order to ensure their suitability for the topic of the thesis.

\subsection{Data analysis}

The collected data consists of scientific papers and cases of programmed trading algorithms. The literature was analysed with the purpose of finding correlations and inconsistencies in the published studies and research on the topic of AT and its market impact. Subject to the literature review were important studies cited in many scientific publications.

The studies were summarized in terms of the datasets they used, their mathematical approach, and their findings, especially their generated returns. Inconsistencies and different results for the research questions were found. The findings of the studies regarding one strategy or one market characteristic were then compared and possible reasons for different findings were outlined. It is worth mentioning that the basic mathematical model of each trading algorithm is published in most papers, but not the entire trading code itself. These findings were synthesized in this thesis to create a better understanding of the topic and to present another perspective. ${ }^{54}$ The literature analysis for

${ }^{54}$ See Torraco, R. J. (2005), p. 358-363. 
the second research question refers to the market impact of AT in general. This approach was taken because it is impossible to determine the market impact of a single AT strategy. On exchanges, one can determine which trades were executed by AT and which by nonAT through different proxies or systems. However, it cannot be determined what particular strategy lies behind a particular algorithm. Due to the limited scope of this thesis, the focus therefore lies on the three main strategies and AT's impact on market liquidity and volatility. 
The trading algorithms subject to this research follow a particular strategy. In the following literature review, the most common strategies and selected studies are presented and discussed in detail.

\subsection{Momentum strategy}

\subsubsection{Definition and basic principle of the strategy}

The momentum strategy - also referred to as the trend-following strategy - has existed for a long time. Its principle is the opposite of the trading motto to buy low and sell high. The leading statement of Driehaus, who is considered the father of this strategy, is to buy high and sell at an even higher price. ${ }^{55}$ In momentum trading, a trader buys financial instruments whose value has increased in the past and sells those whose value has decreased. The underlying assumption is that the value of a trading object that has increased in the past will further increase, and vice versa. In AT, the algorithm is programmed so that it follows a momentum strategy. Therefore, it needs only historical price data. Wide varieties of financial instruments that can be subject to algorithmic trading with a momentum strategy are described in the literature and it is manifested in several markets. ${ }^{56}$

\subsubsection{Underlying theories of the momentum strategy}

There is no consensus about the underlying scientific theory behind the momentum strategy. This is why the strategy is explained using risk-based as well as behavioural theories and hypotheses, which are the subject of many scientific articles and studies. ${ }^{57}$ The risk-based explanations generally propose that greater risks can lead to higher returns.

The starting point for explaining the strategy is the efficient market hypothesis (EMH) of Fama (1970). ${ }^{58}$ Its main statement is that “(...) a market is efficient if the prices always

\footnotetext{
55 See online: Marwah, N. (2020).

${ }^{56}$ See Daniel, K. et al. (2016), p. 242; Leseur, M. (2016), p. 9.

${ }^{57}$ See Asness, C. (2014), p. 88.

${ }^{58}$ See Fama, E. (1970), pp. 383.
} 
fully reflect all available information". ${ }^{59}$ Fama uses three main points to support the hypothesis. Firstly, the rate of returns depend on the taken risk of an asset (the fair game model). Secondly, the value of an asset is expected to increase or not change (the martingale model), and thirdly, the price development follows a random walk and reflects only the current information (the random-walk theory). ${ }^{60}$

Because of this, price changes that are dependent on current events and new information are not predictable and, therefore, future prices are not predictable either. ${ }^{61}$ The hypothesis defines three types of market efficiency that depend on the amount of available information.

In the weak form, current market prices include all information that the historical prices provide and thus, the future prices follow a random walk. Abnormal returns are only achievable with a fundamental analysis, but not with a technical analysis. The technical analysis uses only past data to predict the future development of stock prices. In contrast, in the fundamental analysis the intrinsic value of a financial instrument is determined. Therefore, macroeconomic factors, such as economy and industry conditions, as well as microeconomic factors, for instance management quality, are taken into account. ${ }^{62}$

In the semi-strong form of market efficiency, all current public information is included additionally in the current prices. It is assumed that this information is immediately reflected in the prices and abnormal returns cannot be achieved, because all market participants act rationally and have access to public information. Thus, one can get abnormal returns only with insider knowledge and not with the fundamental analysis anymore.

In the strong form of market efficiency, all information, inclusive of insider knowledge, is inducted in the current prices. This means that no one can get abnormal returns from a trade.

\footnotetext{
${ }^{59}$ Leseur, M. (2016), p. 5.

${ }^{60}$ See online: Leseur, M. (2016), p. 5-6.

${ }^{61}$ See Basdekidou, V. A. (2017), p. 2.

${ }^{62}$ See online: Kersch, M. (2014), p. 84-85.
} 
Under the momentum strategy, which does not allow for a random walk of prices, the semi-strong and strong market efficiency aspects of the EMH are not feasible. In fact, the strategy stands in conflict to the hypothesis, caused by its unrealistic assumptions. In addition, the EMH is a much-debated issue. ${ }^{63}$

Other risk-based explanations were studied in relation to the momentum strategy. Johnson (2002) explains momentum returns in the context of firms' growth rates, because he assumes that a positive shock or increase in returns is an indicator of the ensuing longterm growth of the firm, which will inevitably lead to an upward trend in returns.

Silk and Seasholes (2007) have developed another theory including the firms' growth rates as well. They explain higher momentum returns by linking a firm's growth rate and risk profile to each other. When the market value of a company rises faster than its revenues, it causes a higher risk for investors that leads to potential higher returns. Other risk-based momentum theories have been developed by Berk, Green and Naik (1999), Chordia and Shivakumar (2002), Ahn, Conrad, and Dittmer (2003), Pastor and Stambaugh (2003), Zhang (2004), Sadka (2006), Fama and French (2008), Asness, Moskowitz, and Pedersen (2010), ${ }^{64}$ and Rickenberg (2020). ${ }^{65}$

In contrast to the risk-based theories, behavioural theories were also explored to explain the abnormal returns generated with this trading strategy. Market anomalies arise from investors' behaviour and its biases. Most studies agree that abnormal returns are a result of an underreaction or delayed overreaction of traders. When an underreaction takes place, new information influences the prices very slowly, due to several reasons such as the information diffusion between the traders, conservative trading attitudes, or liquidity issues. Evidence exists that investors react slowed to corporate earnings or the announcement of dividends. In an overreaction, prices increase further due to a feedback mechanism and lead to a momentum return. If momentum is caused by investor biases, this would be a rejection of the EMH. ${ }^{66}$ Behavioural studies of the momentum strategy were conducted by Daniel et al. (1998), Barberis et al. (1998), Hong and Stein (1999),

\footnotetext{
${ }^{63}$ See online: Kersch, M. (2014), p. 83-84.

${ }^{64}$ See online: Moskowitz, T. (2010), p. 3-5.

${ }^{65}$ See online: Rickenberg, L. (2020), p. 1-9.

${ }^{66}$ See Asness, C. (2014), p. 89; Brenøe, M. (2018), p. 8; Moskowitz, T. (2010), p. 3.
} 
Grinblatt and Han (2005), Frazzini (2006), ${ }^{67}$ Vayanos and Woolley (2013), and Campbell et al. $(2014)^{68}$.

These behavioural theories affect the markets and are important when analysing AT, because of the existence of human traders alongside automated trading systems.

Obviously, many theories try to explain the rationale behind the momentum strategy and its related returns, but there is no common explanation. ${ }^{69}$

\subsubsection{Selected studies of an algorithmic intraday momentum strategy}

Since the research question focuses on the execution of trading strategies through automated trading systems based on algorithms, the contents and results of algorithmic momentum studies are analysed further. Trading algorithms nowadays involve highspeed systems and cutting-edge mathematics to earn abnormal returns. This complex mathematics is not discussed in this thesis due to its limited scope.

Generally speaking, algorithms often use technical analysis for their trading decisions. This analysis examines past data: under a momentum strategy, only past data are analysed to predict future development of stock prices. It considers factors such as volatility, moving averages (MA), bid-ask spreads, price trends, mathematical ratios, and momentum indicators such as the rate of change or the Sharpe ratio. The latter is widely used for measuring risk-adjusted returns. ${ }^{70}$ To increase profit chances, several algorithms are also able to process qualitative as well as quantitative data, and are therefore able to interpret verbal statements - conducting a Twitter sentiment analysis, for example. ${ }^{71}$

The following algorithms are several of those tested on past data to find evidence for generated returns. The results can be used to improve strategies and the algorithms themselves. Gsell stated in 2006 that algorithms could not execute a momentum strategy, because they worked one-sidedly and so were unable to follow a buy-low/sell-high strategy. ${ }^{72}$ However, with today's AT systems, the execution of a two-sided momentum strategy is possible, as the following sections testify.

\footnotetext{
${ }^{67}$ See online: Moskowitz, T. (2010), p. 1-2.

${ }^{68}$ See Basdekidou, V. A. (2017), p. 2.

${ }^{69}$ See online: Rickenberg, L. (2020), p. 126.

${ }^{70}$ See online: Christensen, H. et al. (2020), p. 13.

${ }^{71}$ See online: Brenøe, M. (2018), p. 7.

${ }^{72}$ See online: Gsell, M. (2006), p. 16-17.
} 


\subsubsection{Study A - Schulmeister (2009)}

In 2009, Schulmeister tried to answer the research question of whether trading algorithms could turn a profit using intraday data. He stated that the returns of 2,580 technical intraday trading models had decreased constantly during the prior decades and were not considered profitable anymore. Schulmeister also determined whether the same models could produce good returns from a 30-minute database. Data from the S\&P 500 Spot and the S\&P 500 Futures Market from 1983 to 2007 were subject to the study.

The author created algorithms that produce buy and sell signals from current movements in prices. In addition, they point out if the trend will continue or revert. Two types of model are presented. The first uses moving averages for its calculation - a short-term MA that includes data from the past 1-10 days, and a long-term MA whose length varies between 10 and 30 days. These are applied to a 30-minute database, or data divided into 30-minute intervals instead of days. These moving average models follow the rule to buy when the short-term MA moves faster than the long-term MA and intersects it from below and vice versa. The second type, momentum models, use percentage rates of change to determine the trading signals. They follow the rule to buy when the trend changes its direction from negative into positive, and to sell when the opposite takes place. Based on these models, Schulmeister presents six different algorithmic rules that generate buy and sell signals at different points in time. ${ }^{73}$

Three rules follow a momentum strategy (see Figure 1), while the others follow a reversal strategy and will be explained in section 4.2.4.1. The basic rule, signal generation 1 (SG1), of both MA and momentum models described above is trend-following. The other constructed rules are modifications of SG1. The second rule, SG2, is also trend-following and executes the trade at a later point of the trend. It generates a buying signal when the MA oscillator crosses a given boundary from below. When this particular oscillator moves below zero, it is switched into a neutral position. The same method is valid, vice versa, for selling. Taking a neutral position means closing the long position (sell) or closing the short position (buy). In the third trend-following rule, SG3, the algorithm generates trading signals at an earlier point of time. Therefore, it switches earlier to a

${ }^{73}$ See Schulmeister, S. (2009), p. 190-192. 
neutral position that means before the oscillator crosses the zero line. The calculations for the upper and lower bounds and the particular oscillators can be found in the study. ${ }^{74}$

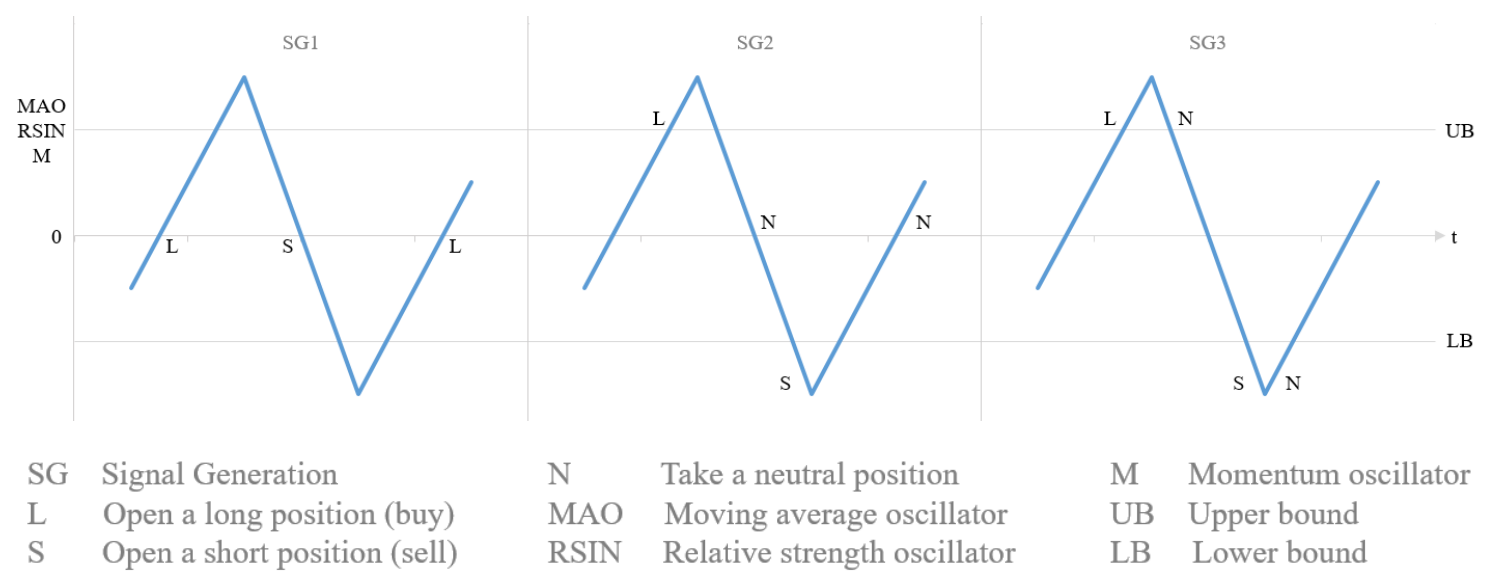

Figure 1: Signal generation rules 1-3 following a momentum strategy

(Source: following Schulmeister, S. (2009), p. 192)

Schulmeister found that these technical trading models are more profitable in intraday trading. With the momentum trading rules, a gross rate of return of 6.8\% (approximately $2 \%$ net return) in the stock futures market based on 30-minute data could be generated. In contrast, the algorithms using a MA performed worse than the ones using the Momentum oscillator.

As reasons for the higher profitability of intraday trading strategies, the author mention the adaptive market hypothesis (AMH) and the rise of speed in trading. The AMH states that a market becomes more efficient due to the evolutionary learning processes of the traders. ${ }^{75}$ This means, basically, that some traders start to use trading rules that prove to be profitable. The more traders use these rules, however, the more unprofitable they become. Therefore, other traders might discover even more profitable trading rules and the cycle of learning and efficiency starts again.

Applied to Schulmeister's study, the profitability of the original trading models decreased, while the 30 -minute models were shown to be profitable. ${ }^{76}$

\footnotetext{
${ }^{74}$ See Schulmeister, S. (2009), p. 192-195.

75 See Schulmeister, S. (2009), p. 199.

${ }^{76}$ See Schulmeister, S. (2009), p. 196-200.
} 


\subsubsection{Study B - Christensen, Turner and Godsill (2020)}

The authors Christensen, Turner and Godsill (2020) recently published a new approach to the returns of algorithmic intraday momentum trading through the application of a Hidden Markov Model (HMM). ${ }^{77}$

Firstly, this model is briefly introduced. The HMM is a special case of a dynamic Bayesian network presenting probability distributions. Besides finance, it is also used in fields such as computer linguistics for speech and writing recognition, and in bioinformatics for gene discovery. The model illustrates a sequence of probability distributions in the form of measurable observations, or so-called 'emissions'. A stochastic process, whose states are not observable, produces these emissions: the process that produces the emissions is therefore hidden. Each state of the process depends only on the previous state.

Calculations of the HMM can be done, for instance, with the Forward-Backward Algorithm, the Viterbi Algorithm or the Baum-Welch Algorithm. These algorithms aim to find hidden parameters of the HMM. ${ }^{78}$

The model used by Christensen et al. assumes a noisy trend and price series that follows a random motion. The price trend is a latent state. To determine the number of latent trend states and parameters, the authors use three mathematical techniques for three algorithmic learning approaches, which are piecewise linear regression (PLR), the Baum-Welch algorithm and the Markov Chain Monte Carlo (MCMC) algorithm. Additionally, they test the approach of a Baum-Welch algorithm with the input of side information. This side information includes the ratio of realized volatilities and the intraday seasonality. Further remarks on the calculations are presented in detail in the study.

The basic assumption in applying the HMM to momentum trading is that the price changes of trading objects can be observed and are measurable, while the state of the underlying trend cannot be observed and thus is hidden (see Figure 2). ${ }^{79}$

\footnotetext{
${ }^{77}$ See online: Christensen, H. et al. (2020), p. 1.

${ }^{78}$ See online: Degirmenci, A. (2014), p. 1-4.

${ }^{79}$ See online: Christensen, H. et al. (2020), p. 4-5.
} 


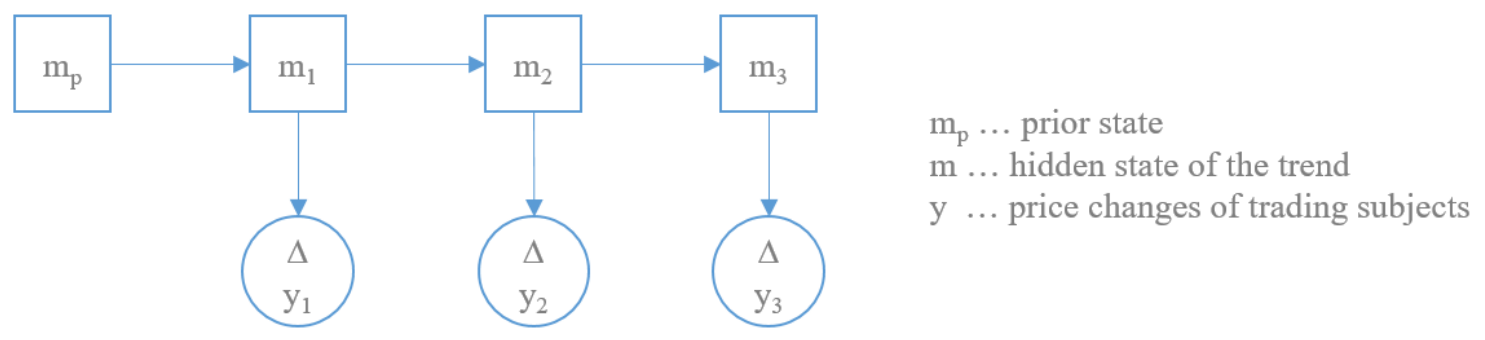

Figure 2: Hidden Markov Model (HMM) applied to trading

(Source: following Christensen, H. et al. (2020), p. 4)

The authors tested the approach on data from the e-mini S\&P 500 Futures from 2011 at one-minute sampling frequency. This gave 258 days of data, with 856 observations per day. The authors do not give exact return rates in their conclusion, but instead provide Sharpe ratios and the number of hidden states.

All techniques deliver similar results, which are that there are two or three hidden states. This is plausible in a momentum strategy; the number of two hidden states relates to an upward/downward-trending momentum, while three hidden states suppose an additional side-moving market state without a significant trend into one direction.

The piecewise linear regression algorithm performs worst. On the other hand, the BaumWelch algorithm performed better than the MCMC due to no scientific reason, but the authors believe that the result comes from the difficulty in correctly using the MCMC algorithm. Both strategies have a high correlation, but MCMC execute the trades less optimally. The Sharpe ratio decreases by approximately $15 \%$ post-cost. Furthermore, the Baum-Welch algorithms with the input of side-information outperform the one without side-information. Their Sharpe value is approximately $10 \%$ higher. This proves that the algorithm is able to consider input information and, thus, has a predictive value. Due to the conclusion from Sharpe ratio to returns, this study supports the thesis that a momentum or trend-following strategy is profitable (pre-and post-cost). ${ }^{80}$

\subsubsection{Study C - Herberger, Horn and Oehler (2020)}

Another result can be found in the analysis of Herberger, Horn and Oehler (2020) of the trading strategies for the DAX 30 stocks traded on XETRA. The authors test 16 momentum strategies consisting of ranking (observing) and holding periods of 15, 30, 45

${ }^{80}$ See online: Christensen, H. et al. (2020), p. 17-20. 
and 60 minutes. The algorithm works in the following manner: the test process starts with the grading of the stocks by their returns generated during the ranking period; then, the stocks with the highest returns are bought for the momentum strategy and form the winning portfolio. ${ }^{81}$ The analysis finds that the returns for the momentum strategy are negative or close to zero. One reason for this might be that the shortest momentum period observed was 35 minutes long (each ranking and holding period comprising 15 minutes, plus 5 minutes skipped between each period). Profitable momentum periods are probably shorter due to the increasing trading speed and thus the faster in-pricing of price-moving news. $^{82}$

\subsubsection{Comparison of the selected studies}

Baz et al. (2015) $)^{83}$ and Brenoe (2018) ${ }^{84}$ show that the momentum strategy is profitable over a longer period of several months, while Schulmeister (2009) and Christensen et al. (2020) provide evidence that the profitability of algorithmic momentum strategies is also viable in intraday trading. However, Herberger et al. (2020) contradict these findings. A reason for this is their use of different datasets. Schulmeister (2009) and Christensen (2020) use data from the S\&P 500 Futures market and gain positive returns, despite the fact that they use different mathematical approaches, different sampling frequencies (30minutes and 1-minute), and data from different periods. Herberger et al. (2020) come to the opposite result of minimal or negative returns, although they use a 35-minute momentum period that does not differ drastically from Schulmeister's study. The publication dates of both works and their examined datasets are several years apart, but a similar momentum period is used. Looking at the technological developments of the years in between the studies and the AMH, one can conclude that the trading period has become shorter, as Herberger et al. (2020) assume as well. Thus, a 35-minute momentum period might be too long to generate abnormal positive returns nowadays. ${ }^{85}$

\footnotetext{
${ }^{81}$ See Herberger, T. et al. (2020), p. 179-188.

${ }^{82}$ See Herberger, T. et al. (2020), p. 194-195.

${ }^{83}$ See online: Baz, J. et al. (2015), p. 17, p. 21.

${ }^{84}$ See online: Brenøe, M. (2018), p. 70.

${ }^{85}$ See Herberger, T. et al. (2020), p. 194.
} 


\subsubsection{Definition and basic principle of the strategy}

The concept of mean reversion - in literature also referred to as the Contrarian strategy is that the prices of financial assets revert to their particular long-term mean. ${ }^{86}$ When there is a decline in prices, the probability is high that it will be followed by a positive price movement, and vice versa. Stock prices will always return in the direction of the mean. ${ }^{87}$ In order to express it correctly in terms of statistics: the more a random variate deviates from its mean, the higher is the probability that the next variate will diverge to a lower degree from the mean. ${ }^{88}$ Time to reversion equates, therefore, to the time of the price return to the mean. Generally, this strategy can be used in every market that fulfils the criteria for intraday trading mentioned in section 2.1.2. At this point, it should be noted that Baz et al. (2015) found that mean reversion in foreign exchanges tends to be slower than for equity and commodities. Its time to reversion is therefore longer. ${ }^{89}$

\subsubsection{Underlying theories of the mean reversion strategy}

The underlying assumption is that the prices of trading objects oscillate around a stable trend. Therefore, a MA of different periods, such as 30 or 90 days, can be calculated and treated as an underlying trend or mean to which prices will revert. ${ }^{90}$

This strategy speaks against the random walk theory, because prices do not move randomly after a price shock, but return to a particular price level.$^{91}$ Furthermore, it stands in contrast to the EMH and the generated returns point to market inefficiency. On the other hand, there are arguments that this is not necessarily the case and that the market is nevertheless efficient. This occurs when the stock value is quantified by the expected returns per share, assuming all available information is included in the prices. Then, mean reversion refers to the mean-reverting expected returns per share. Important papers providing explanations for this strategy have been published since the 1980s and it remains a relevant research subject. Research identifies several factors responsible for the

\footnotetext{
${ }^{86}$ See online: Harvey, C. R. (2018).

${ }^{87}$ See online: Spierdijk, L. (2012), p. 1-4.

${ }^{88}$ See online: Weisstein, E. W. (n.d.).

${ }^{89}$ See online: Baz, J. et al. (2015), p. 13.

${ }^{90}$ See online: Auquan (Ed.) (2017).

${ }^{91}$ See online: Harvey, C. R. (2018).
} 
mean reverting behaviour of stocks: the unreasonable behaviour of noise traders, ${ }^{92}$ unreasonable pricing behaviour because of trends, overreaction to news, and speculative bubbles. ${ }^{93}$

\subsubsection{Relation of mean reversion and momentum}

Before analysing algorithms that execute a mean reversion strategy, it is important to look at the relationship between momentum trading and contrarian trading strategies. The mean reversion strategy generally reflects the opposite of momentum trading. In the research of Plastun et al. (2020) the relationship of momentum, mean reversion and market overreactions in the Ukrainian futures market was analysed in the intraday time frame. Data from 2010 to 2018 was used. ${ }^{94}$

Hong and Stein (1999) have defined significant deviations of an asset price from its average value as overreaction. ${ }^{95}$ The literature also describes a mean reversion or contrarian effect after an overreaction or momentum. Using statistical tests and trading simulations, Plastun et al. make several findings. They determine that the market shows that intraday dynamics on overreaction days are different from the dynamics on usual ones. They also conclude that there is a significant momentum effect on overreaction days, where prices follow only the momentum direction. Furthermore, this effect becomes evident after the first three to four hours of the trading day.

Plastun et al. confirm their hypothesis that a contrarian reaction of prices follows the day after an overreaction, which becomes clear approximately two hours after the beginning of the trading day and lasts the whole trading day. Finally, the authors find that $90 \%$ of the momentum trades are successful, while a contrarian strategy proves to be much less efficient. They show that momentum and contrarian trades can have a causal relationship. However, the results cannot easily be generalized since the Ukrainian stock market is quite unexplored and not a common trading market. ${ }^{96}$

\footnotetext{
${ }^{92}$ See online: Corporate Finance Institute (Ed.) (n.d.) In addition: Noise traders are individual traders whose transactions base on incorrect or insufficient data, such as hypes or rumours.

${ }^{93}$ See online: Spierdijk, L. (2012), p. 2.

${ }^{94}$ See Plastun, A. et al. (2020), p. 24-25.

95 See Hong, H., \& Stein, J. C. (1999).

${ }^{96}$ See Plastun, A. et al. (2020), pp. 24.
} 
Other studies explore both strategies and their relation to each other, such as Jegadeesh and Titman (1993), Ferri and Min (1996), Daniel, Hirshleifer and Subrahmanyam (1998), Lobe and Rieks (2011), Maher and Parikh (2011) ${ }^{97}$, and Heldens (2017). ${ }^{98}$

In addition, Herberger, Horn and Oehler (2020) confirm the causality of momentum and mean reversion. They investigate both trading strategies at the XETRA market and find higher and statistically significant gross returns in reversal strategies, but not in momentum trading strategies. Thus, they find the more efficiency in terms of returns than Plastun et al. Nevertheless, the reversal returns they identify are lower than the transaction fees.

The execution of mean reversion strategies through algorithms are analysed in the following studies. It should be noted here that the duration of momentum and reversal periods have become shorter over the years due to the increasing speed of algorithmic trading. ${ }^{99}$

\subsubsection{Selected studies of an algorithmic intraday mean reversion strategy}

\subsubsection{Study A - Schulmeister (2009)}

In 2009, Schulmeister analysed reversal trading as well as momentum strategy. In section 4.1.3.1 the trading rules SG1 to SG3 were explained with regard to the latter. The following section examines the rules that follow a contrarian strategy (see Figure 3).

The SG4, SG5 and SG6 trading rules aim to find overbought or oversold market states. When the oscillator is positive, but falls under a particular level, the situation is overbought, and if it rises, but is still negative, the situation is oversold. The fourth trading rule generates a selling signal when the situation is overbought and the oscillator crosses the upper bound from above. That means positions are switched from long to short. The same is valid for the opposite case. SG5 includes again neutral positions, as in the momentum rules. When the value of the oscillator declines and approaches to the upper bound from above, then a neutral position is taken and goes short only if the oscillator

\footnotetext{
${ }^{97}$ See Plastun, A. et al. (2020), p. 25-26.

98 See online: Heldens, J. (2017), p. 1.

${ }^{99}$ See Herberger, T. et al. (2020), p. 194.
} 
decreases to zero or below, and vice versa. For both rules, the Relative Strength Index is calculated and used as a gauge of the current market conditions.

In the last trading rule mentioned, SG6, an additional upper and lower bound is included, where a neutral position is always hold, and when the oscillator takes a value that lies between either the two upper or the two lower bounds. ${ }^{100}$

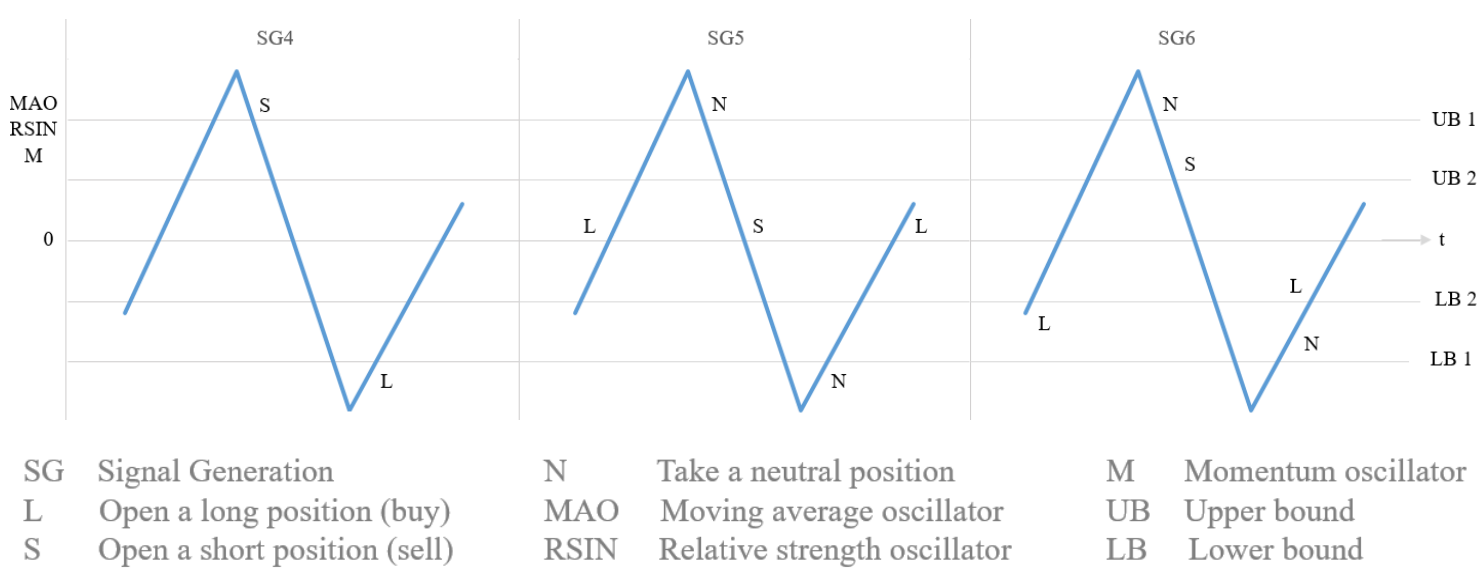

Figure 3: Signal generation rules 4-6 following a mean reversion strategy

(Source: following Schulmeister, S. (2009), p. 192)

The contrarian signal generation rules show a higher performance and thus a higher profitability than the momentum trading rules, with an average gross rate of return of 9.1\% (approximately $4.5 \%$ net return). The study determines that an average gross return of $7.2 \%$ is produced by all trading rules acting together, which equates to a net return of $2.6 \%$ per year in the stock futures market, based in the intraday 30 -minute data. This is the overall result, but in the last years of the sample (2004-2007), the models performed worse and gross returns turned negative. This is explained by the author in terms of the AMH and the rise of speed in trading. ${ }^{101}$

\subsubsection{Study B - Wiśniewska (2014)}

At this point, it is relevant to highlight another study based on one-minute intraday data from 2004 to 2006. The study by Wiśniewska, published in 2014, investigates mean

\footnotetext{
${ }^{100}$ See Schulmeister, S. (2009), p. 192-194.

${ }^{101}$ See Schulmeister, S. (2009), p. 196-200.
} 
reversion in intraday foreign exchange trading focused on the Euro (EUR) and the US dollar (USD).

The author tests the mean reversion of the currency pair EUR/USD with an augmented Dickey-Fuller test $(\mathrm{ADF})^{102}$ and concludes that a mean reversion exists in this case. It confirms the theory that the EUR/USD reverts to a mean that changes over time. Therefore, a regression analysis of the moving average of the last bid rates (as an explanatory variable) is executed. With the computations, the authors determine two trading strategies that should be undertaken by automated algorithmic trading systems.

The going-long strategy advocates purchasing EUR/USD initially and selling it afterwards. On the other hand, the short-sell strategy proposes selling EUR/USD and repurchasing it back afterwards. Calculated with a $99 \%$ confidence interval, the average maximum return for the first strategy is $0.005525 \%$ per day while for the second strategy it is $0.006046 \%$. With the calculations and both strategies that provide positive returns on average, the author is able to confirm mean reversion. Thus, the author rejects the market efficiency hypothesis. On the other hand, trading fees are not included in the study, and further research is needed to determine if the strategies are able to provide a net return. ${ }^{103}$

\subsubsection{Study C- Herberger, Horn and Oehler (2020)}

Herberger, Horn and Oehler have also analysed intraday reversal and momentum returns. They used five-minute return data from 2013-2014 from all 30 stocks on the DAX 30 (German blue chips) traded on the platform XETRA. These stocks have extremely low bid-ask spreads and so there is a low risk for biases.

The authors linearly transform the trading frameworks of De Bondt and Thaler (1985) and Jegadeesh and Titman (1993) into an intraday framework. In particular, the authors analyse each 16 momentum and reversal strategies and transform the original ranking (observing) and holding periods of several months or years into minutes. In this way, they gain approximately 27,000 observations per strategy.

\footnotetext{
102 See online: Prabhakaran, S. (n.d.). In addition: The ADF test measures statistical significance.

103 See Wiśniewska, M. (2014), pp. 1.
} 
For each reversal strategy, ranking and holding periods of 60, 120, 180 and 300 minutes are each combined and tested. They use realized transaction prices for the analysis. ${ }^{104}$ The test process starts by grading the stocks according to their returns generated during the ranking period. Then, the reversal portfolio setup takes place. At the beginning of the holding period, the stocks with the lowest returns are bought. This represents the extreme losing portfolio. The authors define algorithms to determine the market-adjusted return of this portfolio. ${ }^{105}$

In order to gain meaningful results, the 5-minute mean and median returns are calculated as well as the standard deviation, skewness and kurtosis. The analysis reveals that all 16 reversal strategies show significant positive mean returns, higher than the market proxy does. This means that the stocks of the losing portfolios experienced a price increase during the holding period. The results also show that a higher return is linked to higher risk. Furthermore, the results are classified as robust due to the high number of stocks and many combinations of ranking and holding periods of different length.

Despite the positive abnormal returns, another point must be mentioned. The study found that the intraday overreactions of stock prices cannot normally be exploited by retail investors. Only institutional investors might make a profit, because they face lower costs than retail investors, especially in short trades. Even so, the investigation showed that due to the high transaction costs at XETRA, institutional investors would be unable to take the profit in this scenario.

Herberger et al. conclude that only HTF traders or market makers (further explained in section 5.1.1) would be able to reach low enough transaction costs to take a profit. Thus, the strategies do not contradict the EMH. For retail traders, it would be more successful to buy a market index. ${ }^{106}$

\subsubsection{Comparison of the selected studies}

The three studies contain data from different markets (S\&P 500 Spot and Futures market, FOREX and XETRA) and from different periods and present a multifaceted overview of

\footnotetext{
${ }^{104}$ See Herberger, T. et al. (2020), p. 180-182.

${ }^{105}$ See Herberger, T. et al. (2020), p. 183-184.

${ }^{106}$ See Herberger, T. et al. (2020), pp. 185.
} 
algorithmic intraday mean reversion strategies. Furthermore, Schulmeister (2009) analyses 30-minute, Wiśniewska (2014) one-minute, and Hernberger et al. (2020) fiveminute data. However, all authors arrive the result of minimal or no positive returns. Schulmeister therefore highlights an increase in trading speed and Hernberger et al. (2020) mentions the high transaction costs of XETRA as reasons. The returns in Wiśniewska's (2014) research are also very small and do not include transaction costs. This is possibly because the FOREX market is often subject to statistical arbitrage. In particular, pairs trading executed via HFT takes place, ${ }^{107}$ so that trading only one exchange rate might offer lower profits. Therefore, another sampling frequency or a different algorithm might come up with higher returns.

Nevertheless, many traders try their luck and construct reversal-trading algorithms by themselves. In order to analyse overbought and oversold markets, indicators of technical analysis are used commonly for shorter periods. Algorithms for a reversal strategy might include the Relative Strength Index, the Stochastic Oscillator (as in Herberger et al.'s research, 2020), moving averages, Bollinger Bands, and the Elliott wave principle. ${ }^{108}$

\subsection{Arbitrage strategy}

\subsubsection{Definition and basic principle of the strategy}

Arbitrage is an intraday trading strategy where a profit is generated by buying an asset on one exchange and selling it for a higher price on another exchange nearly simultaneously. ${ }^{109}$ The definition is common, but does not cover all of the many kinds of arbitrage, which is a multifaceted term. In a wider sense, it can be defined as “(..) a set of trade operations based on a certain model that yield profit at negligible risk". ${ }^{110}$ The latter point is important, because the literature often classifies arbitrage profits as completely risk-free, which is not achievable under real market conditions. ${ }^{111}$

This strategy aims to exploit the pricing differences of financial instruments. These price discrepancies are based on market inefficiencies, caused by not including the latest news

\footnotetext{
${ }^{107}$ See online: Werl, P. (2014), p. 59.

${ }^{108}$ See online: Forex Training Group (Ed.) (n.d.).

${ }^{109}$ See McIntosh, C. (2013).

${ }^{110}$ See online: Werl, P. (2014), p. 5.

${ }^{111}$ See online: Werl, P. (2014), p. 5.
} 
immediately in the prices on all exchanges. Arbitrage can be find on markets with high transparency and liquidity. For retail investors, emerging markets might be profitable due to the lower competition and lower arbitrage activity. Currency pairs are a common subject of arbitrage. ${ }^{112}$

\subsubsection{Types of Arbitrage}

Arbitrage trading is a complex issue split into deterministic and statistical arbitrage. The first kind guarantees a certain profit, which cannot be calculated ex ante, because of potential market rate changes in the future. Sure value assets, such as gold and other raw materials, as well as some public bonds, belong to the deterministic type of arbitrage assets.

In statistical arbitrage, profits are estimated with mathematical models. The trading signals are created by statistical rules and the strategy is market neutral. That means that there is no correlation with other market returns. Statistical arbitrage is so named because the expected risks are low. This comes from the rule of large numbers. Applied to trading, it states that returns are expected to manifest themselves and make the strategy profitable despite some losses. This in turn means positive profits are not guaranteed and certain risks can arise.

Examples include execution risk, when it is not possible to execute the buy and sell transaction of the different assets simultaneously or in a very short time. Furthermore, there is the risk of mismatch, when the bought and sold assets are not identical. Counterparty risk is present when the other transaction party rejects the trade and it fails. ${ }^{113}$ Returns can only be generated when the prices exceed the no-arbitrage zone, where the returns are higher than the transaction costs. Thus, arbitrageurs mostly trade large volumes to make transactions profitable. On the other hand, this means that huge losses are possible when a mistake occurs. The large volumes and related risks lead to the use of the strategy by mainly institutional investors. ${ }^{114}$

\footnotetext{
${ }^{112}$ See online: Werl, P. (2014), p. 6.

${ }^{113}$ See online: Trading Investment (Ed.) (2015).

${ }^{114}$ See online: Werl, P. (2014), p. 28.
} 
Further classification methods for arbitrage are also possible. These include distinguishing arbitrage by the asset classes involved, or the markets - such as bilateral arbitrage and multilateral arbitrage - as well as by the trade location, for instance intraand inter-exchange arbitrage. ${ }^{115}$ Numerous statistical arbitrage algorithms rely on the concept of mean reversion in order to reduce the risk. ${ }^{116}$

\subsubsection{Underlying theories of the arbitrage strategy}

Using an arbitrage strategy to make profits relies on market inefficiencies that contradict the EMH. Additionally, the strategy stems from the Arbitrage Pricing Theory (APT) devised by Ross (1976) that has its origin in the Capital Asset Pricing Model (CAPM) by Sharpe and Litner (1964). Both theories were developed from the original Portfolio Theory of Markowitz (1952) ${ }^{117}$. The ATP tries to improve on the CAPM by explaining the risk-return relationship with multiple factors and without a market portfolio. The expected return is dependent on every individual risk factor. ${ }^{118}$ Firstly, relevant influencing factors must be determined. Then it is important to define the premium that investors should demand, at risk-free interest, for taking on a particular risk. After this, it is necessary to identify how certain risk factors might influence the financial instruments and how sensitive they are to each one. The stronger the asset reacts to the risk factor, the higher the beta value is. Then, the expected return is calculated. ${ }^{119}$

\subsubsection{Selected studies of an algorithmic intraday statistical arbitrage strategy}

Since arbitrage trading is highly multi-faceted, with many strategy types, the following section focuses on statistical arbitrage strategies, such as pairs trading reflecting bilateral and multilateral arbitrage. It should be mentioned here that, due to the speed of trading and information processing, arbitrage strategies are executed mainly in high-frequency trading. ${ }^{120}$

\footnotetext{
${ }^{115}$ See online: Werl, P. (2014), p. 6-7.

116 See online: Werl, P. (2014), p. 36.

${ }^{117}$ See online: Marling, H. et al. (2012), p. 1-2.

${ }^{118}$ See Kisman, Z. et al. (2015), p. 184-185.

${ }^{119}$ See online: Heiniger, F. (2015).

${ }^{120}$ See online: Werl, P. (2014), p. 28.
} 


\subsubsection{Study A - Werl (2014)}

In 2014, Werl developed a multilateral arbitrage algorithm and tested it using data from East Asian currency exchange rates from January to May 2014. ${ }^{121}$ The written code, which consists of more than 2,000 lines, involves an algorithm that searches for an arbitrage opportunity and an algorithm which produces all possible arbitrage loops for triangular, quadrangular and quintangular arbitrages.

Subject to arbitrage are 17 currency pairs, for example CNY/HKD indicating the currencies Chinese Yuan/Hong Kong Dollar. Arbitrage loops consist of three, four or five exchange rates. An example of a triangular loop is buy KRW/TWD, sell HKD/TWD, buy HKD/KRW. ${ }^{122}$

The algorithm analyses last prices of the currency pairs and detects arbitrage opportunities that fall in the predetermined time frame. Then, the algorithm aims to find arbitrage for all kinds of the arbitrage loops. After this step, the algorithm analyses different information for every single arbitrage loop, which are 268 analyses in sum. Furthermore, it executes an analysis for each loop length (meaning for all cumulative triangular arbitrages, quadrangular and quintangular ones) that equals three analyses. In addition, it undertakes one overall study for all detected arbitrage loops cumulated. For all analyses, indicators such as average, mode and median returns are computed.

Regarding the arbitrage loop length, 34 triangular, 82 quadrangular and 152 quintangular arbitrage loops offered more than 350,000 arbitrage opportunities. Most of the opportunities were provided by quadrangular and triangular loops. Although there were a high number of quintangular loops, $60 \%$ of them did not offer arbitrage opportunities.

Evaluating the output of the algorithm, it was detected that the triangular arbitrages were most profitable with an average annual return of $4.14 \%$ and a median annual return of $0.6 \%$, while the quintangular were least profitable. The calculated indicators show the inequality of returns between the arbitrage loops. The authors define those arbitrage loops that offer the most arbitrage opportunities and the most profitable ones. They come to the conclusion that the pairs of the currencies the New Taiwan Dollar (TWD), the South Korean Won (KRW) and the Hong Kong Dollar (HKD) result in the most profits and

\footnotetext{
${ }^{121}$ See online: Werl, P. (2014), p. 53.
}

${ }^{122}$ See online: Werl, P. (2014), p. 63. 
their pricing may lack market efficiency. The authors advise not to use the arbitrage strategy to generate profits on all markets, but rather to focus on certain currency pairs and a few arbitrage loops. ${ }^{123}$

\subsubsection{Study B - Stübinger and Schneider (2017)}

Stübinger and Schneider (2017) tested another algorithm executing statistical arbitrage in pairs trading. S\&P 500 minute-by-minute stock price data from 1998 until 2015 served as a database for the study.

For pairs trading, the authors follow the framework of Gatev $(1999,2006)$. Assets of synchronous stocks, which prices converged prior, are formed into pairs. Then the price spreads are analysed. The undervalued stock is bought, and the overvalued stock is sold short with the assumption of generating a profit, because the prices will revert back to their historical mean. ${ }^{124}$ The authors define formation periods of 10 days and trading periods of five days. In the formation period, pairs are formed with three different approaches: the Euclidean distance, the Pearson correlation coefficient, and the fluctuation behaviour of the spread between the assets. In the trading period, the authors define individual thresholds for top pairs. This threshold has an upper and lower border that equals the historical equilibrium plus/minus x standard deviations. If the price spread exceeds the upper or lower band, the trading position is opened, and closed when the spread reverts to the historical equilibrium. In order to define the bands, three approaches are used again, which are static threshold, varying thresholds, and reverting thresholds.

Combining all the approaches of the formation and trading periods, the authors come up with nine different trading strategies that are executed for the top 20 stock pairs. They find that all annualized returns after transaction costs (except one) are positive. The maximum annualized return equals $37.85 \%$. On the other hand, the returns show a high variance and low Sharpe ratio. The authors find the most profitable pairs by combining the Euclidean approach with varying thresholds, coming up with significant returns. Furthermore, they investigate the development of pairs trading and come to the conclusion that performance is high during market crises. The performance of pairs trading strategies declines over time, but one can still execute profitable trades.

\footnotetext{
${ }^{123}$ See online: Werl, P. (2014), p. 54-65.

${ }^{124}$ See Stübinger J. et al. (2017), p. 650-652.
} 
Algorithmic high-frequency pairs trading strategies ranging from 15-minute to 1millisecond data have also been tested by Dunis et al. (2010), Kishore (2012), Miao (2014), Gundersen (2014), Vaitonis and Masteika (2016), Landgraf (2016), Liu et al. (2017), and Stübinger and Endres (2017). ${ }^{125}$

\subsubsection{Study C - Stübinger and Schneider (2019)}

Stübinger and Schneider have conducted another study regarding statistical arbitrage based on the data and findings of the previous research from 2017. The strategy they have developed is intended to detect mean-reverting overnight price gaps and aims to profit on price anomalies in the first few minutes of the trading day. Their arbitrage framework relies on a jump-diffusion model that captures the price dynamics. As in the previous study, a formation period and a trading period were subject to this strategy. In the first period, the Barndoff-Nielsen and Shepard (2004) jump test was executed by an algorithm and selected the 10 most suitable stocks. Those 10 stocks were transferred in the one-day trading period. They concluded that their algorithmic trading strategy produced significant annualized returns of $51.47 \%$ after transaction costs, and thus outperformed strategies that were tested against the algorithm, such as the S\&P 500 buy-and-hold strategy. ${ }^{126}$

\subsubsection{Study D - Leung and Lee (2020)}

Professor Tim Leung has published several scientific papers in the field of algorithmic trading strategies. In a study from 2020, Leung and Lee focus on an optimized exit rule on intraday pairs trading. The authors optimize the positions for all asset pairs. With this, the value of the constructed portfolio is best fitted to an Ornstein-Uhlenbeck (OU) $)^{127}$ process in consequence of the maximum likelihood estimation.

Since timing is a very important factor for generating profits in trading, Leung and Lee build entry and exit rules and examine trading profitability. The authors use data from 2012-2019 of minute-stamped traded prices and use hourly price sampling for their

125 See Stübinger J. et al. (2017), pp. 653.

${ }^{126}$ See Stübinger, J. et al. (2019), p. 1-3.

${ }^{127}$ See online: Yeo, D. (2014). In addition: The Ornstein-Uhlenbeck describes a stochastic process which is mean-reverting over time. 
analyses. The trading assets include stocks, exchange traded funds (ETF), currencies, index futures, and commodity futures from different markets. ${ }^{128}$

Firstly, they set up a formula for the portfolios and model the mean reverting portfolio price behaviour that fits an OU process and includes a factor for the Brownian motion. Then, they optimize the mean reversion with the maximum likelihood estimation. In order to test if the determined parameters fit the model, the authors simulate 100 or more OU price paths.

Following this, they compare the average log-likelihood from the simulated paths with the maximum average log-likelihood from the empirical prices. The result shows that a three-month lookback-period best fits the OU model. They accordingly adapt their pairs formula with a time-dependent factor. With this, they construct a trade exit rule that determines a critical price level for the trade liquidation in terms that maximize profits.

Finally, the researchers test their algorithm on the data. They include fees for trade execution while measuring profits. Furthermore, they use a 30-hour standard deviation and a 30-hour simple moving average to measure the performance of the trading exit rule. At every market opening (NYSE market opening time), the model parameters are updated and at every hour the algorithm checks for trade entry and for liquidation when the parameters reach a particular value. This is performed for the baseline model, without the optimal exit rule, and for the authors' model, including the rule.

As result, the framework proves as profitable for arbitrage pairs trading. The Sharpe ratio increases by 0.7 and the daily turnover decreases by $34 \%$ on average for seven of eight tested pairs. The performance is measured for the portfolio as a whole, consisting of the eight pairs as well. The annualized return is $7.4 \%$, which is $2 \%$ higher than for the portfolio without an optimal exit rule, while the Sharpe ratio increases to 1.43. Daily turnover decreases by $35 \%$.

${ }^{128}$ See online: Lee, D. et al. (2020), p. 1-3. 
Another finding of the study was that the optimal exit level is broader in periods with high volatility. The authors define their algorithm as profitable and applicable to several asset classes. ${ }^{129}$

\subsubsection{Comparisons of the selected studies}

In conclusion, all analysed studies obtain positive returns, despite their use of different data periods from different markets. Werl (2014) uses data from the FOREX market, Stübinger and Schneider (2017/2019) from the S\&P 500 stock market and Leung and Lee (2020) from several markets including currencies, futures, ETFs and stocks. Werl (2014) and Stübinger and Schneider (2017) determine positive returns generated by their algorithmic trading models that have a high variance. This means that there is an inequality in the returns of different arbitrage loops or pairs. Stübinger and Schneider (2019) also reached an outperformance of conventional strategies. Furthermore, Leung and Lee (2020) developed a trading rule, which generated higher returns than a portfolio without such an optimal exit rule.

The recent literature under review displays more of a consensus regarding the returns of the algorithmic arbitrage strategy compared with the momentum and mean reversion strategies. The difference is that arbitrage is mostly found in high-frequency trading, which has increased due to technological developments. ${ }^{130}$ Furthermore, fewer studies exist on the topic of algorithmic momentum and mean reversion strategies for algorithmic intraday trading. Due to the fact that arbitrage is mostly used in HFT and consequently in intraday trading, more literature can be found.

\subsection{Further trading algorithms and strategy components}

Besides momentum, mean reversion and arbitrage, there are of course a number of other AT strategies. However, many trading algorithms unite and combine more than one strategy in a single trading system. For these combined algorithms, which cannot be assigned to a single strategy, it is not possible to compare returns as in the previous sections.

\footnotetext{
${ }^{129}$ See online: Lee, D. et al. (2020), p. 4-16.

${ }^{130}$ See online: Werl, P. (2014), p. 28.
} 
The following algorithms can be classified as speed advantage and accuracy advantage algorithms. The speed advantage is mainly exemplified by HFT whereas the accuracy advantage results from the evaluation of more various data. ${ }^{131}$ Both advantages will be further explained in section 5.2.2.2.

\subsubsection{Speed Advantage algorithms}

\section{Spread capturing algorithms:}

Using this class of algorithm, liquidity providers buy and sell securities constantly. With this, they generate revenues from the bid-ask spreads (further explained in section 5.1.2) in prices through working as intermediaries and filling the gaps between market participants. ${ }^{132}$

\section{Rebate trading algorithms:}

Rebate trading algorithms search for unequal fee arrangements on trading venues. Traders who trade large volumes and remove liquidity from the market often have to pay higher fees. The principle of liquidity will be further explained in section 5.1.1. By comparison, traders who provide market liquidity are subject to lower fees or rebates. The algorithms post offers in order to catch these rebates. ${ }^{133}$

Volume weighted average price (VWAP) and time weighted average price (TWAP) algorithms:

VWAP and TWAP strategies are often employed in trading systems, but are rarely the only strategy an algorithm follows. VWAP and TWAP mainly belong to the technical analysis indicators and serve as intraday price benchmarks. ${ }^{134}$

The VWAP presents the average price of all transactions of an asset in a particular period that is weighted by each trade's volume. Thus, the influence of large volume trades is higher on the benchmark. ${ }^{135}$ The period in which a trade should take place is divided into equal slots. The exact volume traded per slot is then determined by the VWAP

\footnotetext{
${ }^{131}$ See online: Gamzo, R. (2017), pp. 213.

${ }^{132}$ See online: Gamzo, R. (2017), p. 40.

${ }^{133}$ See online: Gamzo, R. (2017), p. 41.

${ }^{134}$ See online: Fränkle, J. (2010), p. 36-40.

${ }^{135}$ See online: Gamzo, R. (2017), p. 41-42.
} 
benchmark. ${ }^{136}$ When the transacted price of a buy trade is lower than the VWAP, it is favourable, and vice versa for sell trades. The use of this metric should help to reduce execution costs and balance the liquidity demand. Thus, it should not cause extreme volatility. ${ }^{137}$

The TWAP has a similar aim. Time slots of a desired trading period are formed again. In contrast to the VWAP, the trade volume is distributed in similar parts over this time slots. An example therefore would be to buy 30,000 shares in one hour. This result in six buy transactions with 5,000 shares each. ${ }^{138}$ Thus, the market impact is reduced in comparison to execute a single trade with a large volume at once. ${ }^{139}$

\section{Implementation shortfall algorithms:}

Another algorithm class includes what are known as implementation shortfall algorithms. Their aim is to unite the least possible influence on the market with a the risk of appropriate timing. Large orders that are executed as a whole have a big market impact, while split and time-shifted orders are exposed to the risk of price changes. Thus, the algorithms evaluate past data and set an order process. With this, large orders are divided in the least amount of sub-orders that is possible. ${ }^{140}$

\section{Adaptive execution algorithms:}

These algorithms are similar to the previously mentioned VWAP and TWAP. The difference is that the algorithms are able to align themselves and thus the order execution to new market situations. ${ }^{141}$

\section{Liquidity detection algorithms or 'sniffing' algorithms:}

Algorithms following the liquidity detecting principle try to spot large orders of other market participants. Some of these algorithms have also the ability to detect splitted or hidden orders. When the algorithm detects large orders, it can anticipate price movements and use this information for its own order placement. ${ }^{142}$

\footnotetext{
${ }^{136}$ See online: Fränkle, J. (2010), p. 36-40.

${ }^{137}$ See online: Zhou, H. (2017), p. 80-83.

${ }^{138}$ See online: Gamzo, R. (2017), p. 42.

${ }^{139}$ See online: Fränkle, J. (2010), p. 43.

${ }^{140}$ See online: Gamzo, R. (2017), p. 42.

${ }^{141}$ See online: Gamzo, R. (2017), p. 41-42.

${ }^{142}$ See online: Gomber, P. et al. (2011), p. 28-29.
} 


\subsubsection{Accuracy Advantage Algorithms}

Dataltext-mining algorithms:

These algorithms search for hints of future price movements on huge databases regarding different markets and asset classes. These databases can now contain trillions of observations. ${ }^{143}$ The algorithms are able to set big data from several databases in relation to each other and draw conclusions. In text mining, the algorithms can process textual information into formats that are useable by an algorithm. ${ }^{144}$ Therefore, algorithms are able to undertake a Twitter sentiment analysis. Different keywords can be set prior to analysis and messages classified into categories such as positive, negative, or neutral. With this information, the algorithm adapts its trading orders. ${ }^{145}$

\section{Neural network algorithms:}

Neural networks belong to the state-of-the-art class of algorithms designed for machine learning. Neural networks seek to imitate the connections and learning processes of brains. The algorithms learn from training sets and perform various cycles of instructions. By repeating the cycles and changing the chain of actions based on prior performance, the cycle is improved. ${ }^{146}$ They aim to predict market movements have been applied successfully by asset management funds. Trading algorithms that use neural networks are considered to be 'black boxes'. This term is used to describe predictive models that are highly complex or even impossible to understand and reproduce. A reason for this is the huge amount of data processed by the algorithm and the way in which they are set up in interaction with each other. In addition, the algorithm carries out the data processing with the use of hidden layers. ${ }^{147}$ However, due to their ability to find relationships in convoluted datasets, the algorithms can detect trends that are too complex to be discovered by humans alone. Thus, neural networks can serve as a forecasting tool. ${ }^{148}$

\section{Reinforcement learning algorithms:}

Reinforcement learning (RL) algorithms are another class of machine learning algorithms. In contrast to neural networks, the RL algorithms learn dynamically and not from training sets. The algorithms adjust their actions due to permanent feedback and

\footnotetext{
${ }^{143}$ See online: Gamzo, R. (2013), p. 43.

${ }^{144}$ See online: Gamzo, R. (2017), p. 43-44.

145 See online: Souza, T. et al. (2015), p. 1.

${ }^{146}$ See online: Marr, B. (2018).

${ }^{147}$ See online: Brenøe, M. (2018), p. 23.

${ }^{148}$ See online: Gamzo, R. (2017), p. 44.
} 
learn from trial and error. RL algorithms try various actions and learn from the feedback. Then, the algorithms reinforce the actions with positive results. These are improved further until they reach the best outcomes. Related to AT, these are of course the actions with the highest trading return. Several algorithms also combine the deep learning approach of neural networks with RL. ${ }^{149}$

${ }^{149}$ See online: Marr, B. (2018). 
The following chapter focuses on the research question of how AT influences market liquidity and volatility. As previous parts of this thesis have made clear, numerous different AT strategies and algorithms exist. Therefore, it is not possible to measure the market impact of one particular trading strategy that is executed by many different algorithms and traders. As a result, the impact of AT on market liquidity and volatility is examined in general terms. The studies are analysed on this basis.

\subsection{Market liquidity}

\subsubsection{Definition}

As already defined in section 2.1.2, liquidity represents the possibility of executing large volume orders within a desired time without causing significant price changes. In order to assess the function of a trading system, Harris defines liquidity as the most important criterion. The reason is that liquidity shows how effectively buyers and sellers are brought together on the exchange, reflected by bid-ask spreads. ${ }^{150}$ One can also adopt a broader definition of market liquidity, which determines a market as liquid when a trade can be executed without or with little cost, risk or inconvenience. ${ }^{151}$

Markets become liquid through liquidity providers, which include financial institutions such as banks and principal trading firms (non-banks). These parties, also referred to as market makers, are intermediaries and fill gaps (bid-ask spreads) between market participants. Due to these liquidity providers, traders can buy or sell at the desired time without waiting to find a particular seller or buyer. ${ }^{152}$

\subsubsection{Bid-Ask Spread}

The bid-ask spread measures the liquidity of an individual financial asset. It reflects the gap between the highest price a buyer would pay (bid) and the lowest price a seller would request (ask). ${ }^{153}$ Normally, the ask price is higher than the bid price. The spread is lower for actively traded assets and higher in the opposite case. That means that the spreads of

\footnotetext{
${ }^{150}$ See online: Gomolka, J. (2011), p. 5

${ }^{151}$ See online: Tian, Y. (2009), p. 11.

${ }^{152}$ See online: FIA (Ed.) (2017).

${ }^{153}$ See online: Fränkle, J. (2010), p. 24.
} 
assets in liquid markets are generally lower than the spreads in an illiquid market. Liquid securities include, for instance, large-cap stocks and currencies. ${ }^{154}$ Furthermore, one can estimate transaction costs with the bid-ask spread. In an illiquid market with large bidask spreads, transaction costs are high; whereas in a liquid market with small bid-ask spreads, transaction costs are low. Thus, a liquidity premium (transaction cost) arises, which measures the half bid-ask spread when an order is placed. The more illiquid a market is, the higher is the liquidity premium. It belongs to the implicit trading costs. ${ }^{155}$

\subsubsection{Dimensions of liquidity}

Liquidity can be measured according to four dimensions, which are immediacy, market width and market depth, and renewability. Immediacy means the required time to execute a trade to a given price and fixed transaction costs. Market width is described by the placement of large volume orders without a significant market impact. A market is furthermore liquid if a particular market depth is given. This means that transactions can be executed close to a theoretical equilibrium price. ${ }^{156}$ The fourth dimension is renewability, which is the time needed by the market to return to the previous situation after uninformed investors cause a price change. ${ }^{157}$

\subsubsection{The impact of algorithmic trading on market liquidity}

\subsubsection{Hendershott, Jones and Menkveld (2011)}

Hendershott, Jones and Menkveld made a meaningful contribution in this field in 2011 with their research on whether AT improves liquidity. The authors observed a market liquidity increase parallel to the rising use of AT since the mid-1990s. Therefore, they investigated the relationship scientifically. For their analysis, the authors took a sample of NYSE stocks over the period of 2001 to 2005.

Due to the non-observability of AT, the authors used the 'rate of electronic message traffic' as an AT indicator: the higher speed of AT due to a lack of human intermediaries

\footnotetext{
${ }^{154}$ See online: Fränkle, J. (2010), pp. 25.

155 See Kersch, M. (2014), p. 22-23. In addition: explicit trading costs are fees (brokerage, exchange, clearing, settlement) and taxes; implicit trading costs are waiting costs, opportunity costs and the market impact consisting of the liquidity premium and adverse price movements.

156 See online: Gomolka, J. (2011), p. 5.

${ }^{157}$ See online: Kersch, M. (2014), p. 20-21.
} 
equates to higher message traffic than in conventional trading. ${ }^{158}$ The proxy in the study includes particularly order submissions and cancellations. In order to measure liquidity, Hendershott et al. use different spreads ${ }^{159}$ and five-minute and 30-minute price impacts. ${ }^{160}$ With price impact, Hendershott et al. measure gross losses of liquidity demanders resulting from adverse selection. Furthermore, they include the NYSE autoquote that displays a liquidity quote for every stock and causes an increase of AT. The autoquote provides a real-time feedback of trade circumstances and can be processed by algorithms immediately. ${ }^{161}$

The authors carry out several approaches that measure the correlation of AT and liquidity and make a distinction between large- and small cap stocks. The research concludes that AT improves liquidity for large-cap stocks. The authors find that, especially after the implementation of autoquote, AT narrows spreads. This is a result of a decrease of information asymmetry between trading parties, also called adverse selection. For smaller-cap stocks, they find no significant effects, but the authors cannot determine if this is a result of an error in statistical validity or a real fact. Nevertheless, from these findings Hendershott et al. conclude that AT improves market liquidity and thus, market quality as well. ${ }^{162}$

Hendershott and Riordan conducted another study using data from the 30 DAX stocks regarding AT in 2011 and 2013. They found that AT demands liquidity when market conditions are good and transaction costs low, while it provides it in the opposite case. ${ }^{163}$

\subsubsection{Boehmer, Fong and Wu (2015)}

In 2015, Boehmer, Fong and Wu studied the effect of AT on 42 equity markets with intraday data from 2001-2011.

In order to determine AT from all orders and trades, the authors follow the approach of Hendershott, Jones and Menkveld and use a similar AT proxy. The authors use several liquidity measures for the computation. These are the best-quoted intraday spreads per

\footnotetext{
${ }^{158}$ See Hendershott, T. et al. (2011a), p. 6.

${ }^{159}$ See online: Bessembinder, H. et al. (2009), p. 4-6.

${ }^{160}$ See Hendershott, T. et al. (2011a), p. 1-7.

${ }^{161}$ See Hendershott, T. et al. (2011a), p. 13.

${ }^{162}$ See Hendershott, T. et al. (2011a), pp. 16.

${ }^{163}$ See Hendershott, T. et al. (2011b), p. 23; Hendershott, T. et al. (2013), p. 1.
} 
stock, relative effective spreads and the total price impact of the trades. Furthermore, they calculate an illiquidity ratio and test the approach of robustness. ${ }^{164}$

Boehmer et al. come to several findings. On average, a higher degree of AT on the market leads to increased liquidity, faster price volatility, and so to higher market efficiency. Furthermore, the authors find that the market liquidity is lower on days where AT leads to an increase in volatility. Thus, the AT effect in this situation is not desirable. Boehmer et al. come to a similar conclusion as Hendershott et al. (2011), notably that liquidity declines for small-cap stocks when AT increases in the market. In addition, when market making is difficult, the effect of liquidity provision through AT is smaller. The findings are consistent across several markets, but heterogeneous in the cross-section of the analysed financial assets. ${ }^{165}$

\subsubsection{Broussard, Nikiforov and Osmekhin (2020)}

In their work, Broussard, Nikiforov and Osmekhin researched market quality with a dataset from the NASDAQ OMX Nordic research group over 382 trading days from 2010 to 2011. They divide the market participants into algorithmic traders, institutional traders, professional investors and retail traders. ${ }^{166} \mathrm{~A}$ model including dummy variables that present the trader types is subject to the computations. Broussard et al. arrive at several findings. As in the study of Hendershott et al., they find that AT decreases the spreads of the financial assets on the market. In detail, the spreads decrease by $10 \%$ on average compared with retail trading activity and 50\% compared with institutional trading activity. In addition, they determine that AT does not impact spreads or the traded volume on highly volatile days. Regarding liquidity, the authors conclude that algorithmic traders mainly remove liquidity while retail traders supply it. The latter finding stands in contrast to Golub, Glattfelder and Olsen's liquidity-providing algorithm described in the following section. Broussard et al. also define this finding as unique. ${ }^{167}$

\footnotetext{
${ }^{164}$ See online: Boehmer, E. et al. (2015), p. 13-18.

165 See online: Boehmer, E. et al. (2015), p. 1-4.

${ }^{166}$ See online: Broussard, J. P. et al. (2020), p.7. In addition: Algorithmic traders use their own algorithms to trade, institutional traders use algorithms approved by NASDAQ, professional investors execute trades without the use of algorithms and retail traders are non-professionals.

${ }^{167}$ See online: Broussard, J. P. et al. (2020), pp. 4.
} 


\subsubsection{Golub, Glattfelder and Olsen (2017) - The Alpha Engine}

Golub, Glattfelder and Olsen did not study the effect of AT on liquidity as in previous studies, but instead developed a trading algorithm. The so-called Alpha Engines supplies liquidity to the market. Their trading model focuses on the FOREX market, which is highly liquid. Investment strategies that enhance market liquidity are able to create positive market effects. They lead to more stable prices and reduce uncertainty on the market. Thus, the returns of these strategies are the payoff for their value-adding market effect. The authors state, in addition, that there is a large profit potential on liquid markets. The Alpha Engine works in a counter-trending manner and primarily follows a reverting strategy. The strategy is tested on 23 exchange rates with data from 2006 to 2014. The algorithm opens a position when the market overshoots. In addition, positions that go against the trend are maintained or increased. Thus, the algorithm provides liquidity. The algorithm leads to an unleveraged return of $21.34 \% .{ }^{168}$

\subsubsection{Statements by public institutions}

The Markets in Financial Instruments Directive of the European Parliament (2014) states that HFT generates benefits for markets, such as increased market liquidity and narrower bid-ask spreads. It also determines obligations for the liquidity provision of parties that conduct a market making strategy through AT. ${ }^{169}$

The US Securities and Exchange Commission is another public entity that states AT improves market liquidity provisions, particularly when the market is in a normal state and not in a period of extraordinary stress. In the latter situation or during crises, AT might worsen the market conditions, it says. ${ }^{170}$

The Bank of Japan notes similar effects of AT on the market. This institution determines that AT takes place more in Europe and the US than in Japan, but an upward trend is visible there, too. A study was conducted regarding the USD/JPY (Japanese Yen) in the FOREX market. It was found that AT improves market liquidity in common, non-extreme situations, especially liquidity provision through market making. However, the study could not confirm that AT has a significant negative influence on market liquidity in times

${ }^{168}$ See online: Golub, A. et al. (2017), p. 1-6.

${ }^{169}$ See The European Parliament and the Council of the European Union (Ed.) (2014), p. 358-359.

170 See online: U.S. Securities and Exchange Commission (Ed.) (2020), p. 4. 
of market stress. This was observed during the COVID-19 pandemic with data from the end of February until the end of March 2020. ${ }^{171}$

\subsubsection{Comparison of the selected studies and further literature}

The analysed studies come to several similar findings. Hendershott et al. (2011) and Boehmer et al. (2015) conclude that AT improves liquidity, especially for large-cap securities, although they use data from different markets and different periods. The legal documents of the European Commission (2014), the US Securities Exchange Commission (2020) and the Bank of Japan (2020) state as well that AT and HFT improve market liquidity. Further literature that supports this finding include Sellberg (2010), ${ }^{172}$ Hasbrouck and Saar (2013) ${ }^{173}$ and Van Kervel and Menkveld (2019) ${ }^{174}$. Despite literature that confirms the liquidity-providing effect, there is also research that asserts this is not the case. Brogaard et al. (2018) confirm that HFT supplies liquidity, but only when one stock is in an extreme price event, while it demands liquidity if several stocks or the whole market is in a stress situation. ${ }^{175} \mathrm{~A}$ decreasing in liquidity in extreme market stress episodes is also highlighted by the Bank for International Settlements (2017), ${ }^{176}$ whereas the Bank of Japan (2020) could not confirm the thesis. Broussard et al. (2020) conclude that AT mainly removes liquidity from the market in general. However, more literature was found that supports the liquidity-providing function of AT.

\subsection{Market volatility}

\subsubsection{Definition and characteristics of volatility}

Daly (2011) describes volatility as the changeableness of a variable. ${ }^{177}$ More precisely, volatility means large and rapid price changes of securities in capital markets. ${ }^{178}$

Regarding market efficiency, it is important to mention that a market is considered as more efficient the lower the price volatility is. ${ }^{179}$ Furthermore, as liquidity influences the

\footnotetext{
${ }^{171}$ See Fukuma, N. et al. (2020), p. 1-6.

172 See Gomber, P. et al. (2018), p. 15.

${ }^{173}$ See Hasbrouck, J. et al. (2013), p. 1.

${ }^{174}$ See Kervel, V. van et al. (2019), p. 1091.

175 See Brogaard, J. et al. (2018), p. 253-254.

176 See Bank for International Settlements (Ed.) (2017).

${ }^{177}$ See Daly, K. J. (2011), p. 46-47.

${ }^{178}$ See Moles, P. et al. (1997); See section 2.1.2.

${ }^{179}$ See online: Kersch, M. (2014), p. 18.
} 
bid-ask spread for financial assets on the market, so does volatility, too. The more the bid-ask spread of prices grows, the higher the volatility of the underlying asset. Thus, volatility affects the market's liquidity as well. Volatility is often perceived as unpredictable, uncertain, and risky. In the context of financial markets, it is mainly associated with the unpredictability of market price movements and deviations from estimated prices of theoretical models. Therefore, trading activity might decrease sharply when volatility reaches a certain level. Many models try to forecast market volatility, but their predictive power is very limited. However, there are particular factors that influence volatility, such as recessions, which are not predictable. Further factors include the contribution of trading and non-trading days and high nominal interest rates.

For AT, short-term factors are mainly important. Therefore, literature investigates especially the correlation of volatility and trading volumes. ${ }^{180}$ In the short-term, particularly in the intraday periods, the volatility of prices is normally lower than in the comparison of end-of-the-day prices. In highly volatile markets the speed of AT is again very important, because of the fast changes in prices. ${ }^{181}$

\subsubsection{The impact of algorithmic trading on market volatility}

\subsubsection{Boehmer, Fong and Wu (2015)}

When Boehmer et al. analysed the impact of AT on 42 equity markets, ${ }^{182}$ they also evaluated the impact of AT on volatility. The intraday price range from the highest to lowest price per day serves as a volatility measure to represent intraday fluctuations. Additionally, the authors compute absolute values of daily returns, daily market-adjusted returns and intraday return variances as measures for realized volatility. ${ }^{183}$

The authors find that AT increases liquidity and informational efficiency, but also volatility. For the smallest tercile of stocks, AT exacerbates the volatility increase further. Boehmer et al. analyse two reasons for the AT-caused increase in volatility.

\footnotetext{
${ }^{180}$ See Daly, K. J. (2011), p. 46-47.

${ }^{181}$ See online: Kersch, M. (2014), p. 182.

${ }^{182}$ See also section 5.1.4.2.

${ }^{183}$ See online: Boehmer, E. et al. (2019), p. 1-11.
} 
Firstly, higher price volatility results from an increase in market efficiency. In this situation, new information is integrated faster into the prices and causes higher, more desired volatility. In order to test this in the sample, the authors hold the level of informational efficiency constant. However, they find a further increase in volatility through AT. That means the positive volatility through faster price discovery is not the single cause of the increase. Secondly, Boehmer et al. consider if higher volatility originates from the preference of algorithmic traders for highly volatile markets. These traders searching for volatility induce a decreasing market quality. The authors assume that the traders follow a market-making strategy, enter the market when volatility is high and provide liquidity. Therefore, they analyse the influence of volatility and liquidity. However, they find that AT leads to lower liquidity, when it causes a volatility increase and reject their assumption. This is why this kind of volatility is not desirable. Boehmer et al. cannot determine if the volatility increase triggered by AT is more a result of desirable or non-desirable volatility. ${ }^{184}$

In a follow-up study in 2019, Boehmer, Fong and Wu specify that AT increases shortterm volatility in particular. Thus, the daily price range, return variances, and daily return volatility rise as AT increases on the market. Furthermore, the volatility of smaller stocks is increased to a higher degree by AT. As in the previous study, the authors cannot attribute the increasing volatility to more market efficiency, volatility-seeking traders, or volatility increases due to news announcements. ${ }^{185}$

\subsubsection{Gamzo (2017)}

As Gamzo studies the market impact of AT, he divides the algorithmic traders into two different groups, which are represented by System 1 and System 2. System 1 is characterized by superior speed in processing information, while System 2 owns a superior accuracy in computing future variables and is slower than System 1.

With this, both systems have their own informational advantage. The speed advantage of System 1 comes from high-speed market connections and co-location facilities, for example. This enables actors to trade faster, more frequently, and with shorter holding periods. In the short term (intraday, often in only seconds or minutes), the asset price is

\footnotetext{
${ }^{184}$ See online: Boehmer, E. et al. (2015), p. 2-26.

${ }^{185}$ See online: Boehmer, E. et al. (2019), p. 1-4.
} 
rather determined by the order flow instead of fundamental values. Thus, the traders of System 1 generate a profit that consists of the difference of the entry and exit price (and not of the difference between entry price and fundamental value). This is why the order flow is a key focus of the system.

In order to have an accuracy advantage, System 2 traders use information beyond data provided by the order book. The algorithms analyse information, such as news, firm fundamentals and other macro-economic factors. The intrinsic worth of the traded financial assets has more relevance in the computations and a firm-specific forecast is developed. This information are more complex to interpret for algorithms and arrive not as fast as order book information. Both systems include different algorithms explained in section $4.4{ }^{186}$

The author's research investigated how each group of algorithmic traders influenced the market quality. Both types of traders affect the market dissimilarly. Firstly, it is to mention that the authors define volatility as the difference in the temporary and permanent price impact. The System 1 algorithmic traders lead to an increased short-run price impact due to their speed advantage. Thus, it caused higher short-term volatility. On the other hand, System 2 algorithmic traders influence the enduring price impact more. The reason therefore is their slower trading. Thus, they affect mainly long-term volatility. In conclusion, AT as a whole increases short-term price volatility and decreases it in the long-term in Gamzo's model. ${ }^{187}$

\subsubsection{Zhou, Kale and Frino (2020)}

Zhou et al. (2020) examined whether AT increases volatility during periods of market stress. In order to analyse this issue, the authors observe the connection of AT intensity and stock returns on days with high market movements. The underlying dataset consists of equity transaction data of the Australian Securities Exchange from October 2008 until October 2009. Obviously, this period was during the financial crisis. The data contain several information about each trade as well as an indicator that shows if a computer or a human executed the trade. Thus, they do not use a proxy as Boehmer et al. (2015) do, which might cause biases. The analysed market days are qualified as turbulent if they

\footnotetext{
186 See online: Gamzo, R. (2017), p. 74-78.

${ }^{187}$ See online: Gamzo, R. (2017), p. 245.
} 
show an absolute value of market returns higher than $2 \%$. This applied to 39 days, 19 days with an upward-movement, 20 with a downward-movement. ${ }^{188}$

Zhou et al. find that stocks traded algorithmically to a higher degree face a lower volatility. When the market declined by more than $2 \%$, these stocks experienced fewer price decreases and less downward price pressure than stocks with a lower AT intensity. The same is valid for a market increase by more than $2 \%$. Their findings support the AT lowers price pressure and extenuates pricing errors. Furthermore, Zhou et al. analysed the returns on the days after the turbulent period. They find return reversals in stocks with low AT intensity. This implies non-AT or low AT-intense stocks experience a higher market pressure and the prices deviate significantly from the fundamental value. This is not the case for stocks with a high AT intensity. This is why AT tends not to contribute to price volatility. ${ }^{189}$

\subsubsection{Statements of public institutions}

The Markets in Financial Instruments Directive of the European Parliament (2014) states that AT and HFT lead to a reduction in short-time volatility. However, they mention that AT systems can also lead to an increase in volatility. This increase is explained by the overreaction of AT systems to market events. In addition, the condition of a pre-existing market problem must be fulfilled for an AT-caused volatility increase. ${ }^{190}$

The US Securities and Exchange Commission states some types of AT are able to exacerbate market volatility. It is mentioned that a momentum effect in stock prices might appear through AT strategies that depend on volatility. These strategies increase the sale of financial instruments, when the prices fall what is an indicator for a rise in volatility. This leads to a downward trend in prices while volatility increases. In terms of HFT, the commission states that there are studies supporting the thesis that HFT reduces intraday volatility, while others reject this. ${ }^{191}$

\footnotetext{
${ }^{188}$ See Zhou, H. et al (2020), p. 3-5.

${ }^{189}$ See Zhou, H. et al (2020), p. 1-2.

${ }^{190}$ See The European Parliament and the Council of the European Union (Ed.) (2014), p. 359.

${ }^{191}$ See online: U.S. Securities and Exchange Commission (Ed.) (2020), p. 30-45.
} 


\subsubsection{Comparison of the selected studies and further literature}

The literature regarding AT's impact on market volatility comes to different conclusions. Gsell (2008), Chaboud, Hjalmarsson, Vega and Chiquoine (2009), Brogaard (2010), Groth (2011), Hendershott, Jones and Menkveld (2011) ${ }^{192}$ and Zhou (2020) ${ }^{193}$ analyse different data from different exchanges and find no increase in volatility through AT. Hasbrouck and Saar (2013) conclude the similar effect and add that AT even lowers shortterm volatility. ${ }^{194}$ An example therefore is the Alpha Engine of Golub et al. ${ }^{195}$ Their trading algorithm buys and sells counter-trending and thus, works against a trend reducing volatility.

On the other hand, Zhang (2010), Martinez and Roşu (2011), Boehmer et al. (2015) Foucault, Hombert and Roşu (2016) ${ }^{196}$ and Kelejian and Mukerji (2016) ${ }^{197}$ represent the findings that AT leads to an increase in market volatility. The analysed studies of Gamzo (2017) and Boehmer et al. (2019) specify their finding on an increase in short-term volatility through AT. Gamzo further states that there is a long-term decrease in volatility caused by AT. ${ }^{198}$

In terms of HFT, Boehmer, Li and Saar (2018) come to another result. They find that volatility decreases through HFT. The reason therefore is the high competition between HFT market makers. ${ }^{199}$ Brogaard et al. (2018) find that HFT stabilize prices in high volatility periods instead of increasing it. This is explained with the fact of trading against price movements. ${ }^{200}$ The opposite is found by Roşu in 2019. The author concludes that when more high-frequency traders enter the market, volatility increases. ${ }^{201}$

The US Securities and Exchange Commission states that some types of AT exacerbate market volatility while others decrease it and stabilize the markets. ${ }^{202}$

\footnotetext{
${ }^{192}$ See online: Gamzo, R. (2017), p. 65-66.

193 See Zhou, H. et al (2020), p. 1.

${ }^{194}$ See online: Gamzo, R. (2017), p. 57.

195 See section 5.1.4.4.

196 See online: Gamzo, R. (2017), p. 18.

${ }^{197}$ See Mukerji, P. et al. (2019), p. 68-69.

${ }^{198}$ See online: Gamzo, R. (2017), p. 245.

${ }^{199}$ See Boehmer, E. (2018), p. 2272-2273.

${ }^{200}$ See Zhou, H. et al (2020), p. 3.

${ }^{201}$ See Roşu, I. (2019), p. 2-3.

${ }^{202}$ See online: U.S. Securities and Exchange Commission (Ed.) (2020), p. 45-46.
} 
Due to ongoing research into automated trading and its steady development, AT is a significant issue for capital markets. This thesis gives an overview of the AT strategies momentum, mean reversion and statistical arbitrage. In the process, studies by different authors over many years and various research approaches have been analysed. The evaluation of several studies for each strategy revealed different profits that could be generated by the trading algorithms.

The literature varies on the question of whether the algorithmic momentum strategy is profitable. Herberger et al. (2020), using a 35-minute momentum period, find that the trading strategy does not generate positive abnormal returns. ${ }^{203}$ In contrast, Christensen et al. (2020) created an algorithm that turns out to be profitable for a one-minute momentum period. This finding indicates greater profitability over a shorter momentum period. ${ }^{204}$ This is logical given the increasing market share of HFT. The German Federal Bank (2016) also supports this hypothesis. It states that HTF has a share of approximately $50 \%$ of all trading activities in liquid European and US-American markets. ${ }^{205}$

Regarding the mean reversion strategy, there is a greater agreement. Although the studies analysed in section 4.2.4 use data from different periods and different algorithms, all approaches show minimal or no profits. In contrast to this, algorithms following a statistical arbitrage strategy provide positive net returns. ${ }^{206}$ Once again, the reason can be largely attributed to HFT, in which arbitrage mainly takes place. Due to the increasing market speed, the price differences that arbitrage tries to exploit change faster and so faster trading is required to gain a profit. ${ }^{207}$

In general, it can be concluded that AT is profitable for momentum and especially arbitrage strategies in the HFT sector.

\footnotetext{
${ }^{203}$ See online: Herberger, T. A. et al. (2020), p. 185.

${ }^{204}$ See online: Christensen, H. et al (2020), p. 19.

${ }^{205}$ See online: Deutsche Bundesbank (Ed.) (2016).

${ }^{206}$ See section 4.3.4.

${ }^{207}$ See online: Deutsche Bundesbank (Ed.) (2016).
} 
Besides the evaluation of the three AT strategies, further trading algorithms were mentioned. Due to the large number of strategies and its relevance for capital markets, the impact of AT on market liquidity and volatility was analysed further.

In terms of the influence of AT on market liquidity, researchers mainly agree in their conclusions. The majority of research finds that AT and HFT improve liquidity and have a positive effect on the market. ${ }^{208}$ In addition, Hendershott et al. (2011) and Boehmer et al. (2015) determine that the liquidity-providing effect is valid specifically for large-cap financial assets. There is no consensus on whether AT still provides liquidity when there is a situation of market stress.

Furthermore, the literature provides a range of opinions on the effects of AT and HFT on volatility. Section 5.2.2 evaluates those studies that argue whether AT increases or decreases market volatility. Gamzo (2017), for instance, determines there is an increase in short-term and a decrease in long-term volatility through AT. ${ }^{209}$ In addition, it is worth mentioning that HFT was found responsible for the so-called 'Flash Crash' of 2010. The high-speed automated trading program of a US company placed a selling order of S\&P futures contracts worth 4.1 billion USD. The execution of the entire order took only 20 minutes and caused orders of other automated trading systems. As a result, there was considerable volatility and high liquidity fluctuations occurred. After this event, it was concluded that AT and HFT programs play a critical role in capital markets. ${ }^{210}$

In conclusion, AT and HFT are able to influence market liquidity and volatility positively, but can also exacerbate the market state.

Therefore, risks and potential future regulations need to be explained briefly. Technological developments are resulting in increasingly sophisticated trading algorithms such as neural networks, reinforcement learning and other machine learning algorithms. These algorithms are considered black boxes and carry a risk. Furthermore, sniffing algorithms are able to manipulate the market through detecting trading activities of other market participants. ${ }^{211}$ Market manipulation through algorithms can also take

\footnotetext{
208 See section 5.1.4.

${ }^{209}$ See online: Gamzo, R. (2017), p. 245-246.

${ }^{210}$ See Lin, T. C.W. (2017), p. 1260-1262.

${ }^{211}$ See online: Gamzo, R. (2017), p. 43-44; See section 4.4.1.
} 
place in form of pinging and spoofing. These HFT tactics aim to gain information about the trading intentions of other market participants. In both strategies, many orders are placed, but with the intention of cancelling them before they can be executed. The placement of these orders creates a false picture of the current market state. Thus, the reactions of other market participants are provoked that reveal their buying or selling intentions. The pinging or spoofing party then uses this information to their advantage. ${ }^{212}$

Overall, these state-of-art algorithms as well as market manipulation algorithms carry particular risks for the field of AT. The more complex and opaque the algorithms become, the higher the risk they represent. Besides this, the dependency on high-speed actions presents another risk. ${ }^{213}$ The increasing complexity and speed of AT as well as growing volatility over time will lead to new regulations and laws. ${ }^{214}$ This will occur gradually and in a piecemeal fashion: spoofing has been illegal in the US since 2010, while it was still being executed by European banks in 2018. ${ }^{215}$

The points outlined in this thesis are intended to encourage further research. Since many trading algorithms and a large number of strategies exist that are the subjects of current research and development, they represent an issue of major importance for capital markets. In order to get a clearer view of AT's influence on liquidity and especially volatility, studies about the market movements during the COVID-19 pandemic would be pertinent. This would enable algorithmic traders and investment firms to develop their algorithms further to ensure positive impacts on market quality. In order to decrease the risk of market manipulation and increase the transparency of trading, research and development of the connection of AT and blockchain technology is purposeful with the aim of reproducing the chain of trades and increasing transparency. ${ }^{216}$

\footnotetext{
${ }^{212}$ See online: Stenfors, A. (2018), p. 6-7.

${ }^{213}$ See Lin, T. C.W. (2017), p. 1274.

${ }^{214}$ See Daly, K. J. (2011), p. 46.

${ }^{215}$ See online: Corporate Finance Institute (Ed.) (n.d).

${ }^{216}$ See Brunner, A. et al. (2017).
} 


\section{Publication bibliography}

Admiral Markets (Ed.) (2020): Intraday Handel - So funktioniert der kurzfristige Handel mit DAX, Gold und Co. Updated on 03/08/2020. Available online at https://admiralmarkets.de/wissen/articles/forex-strategy/intraday-trading, checked on 15/11/2020.

Ansi, A.; Ben Ouda, O. (2009): How Option Markets Affect Price Discovery on the Spot Markets: A Survey of the Empirical Literature and Synthesis. In International Journal of Business and Management, 2009, Vol. 4, No. 8, pp. 155-169.

Asness, C.; Frazzini, A.; Israel, R.; Moskowitz, T. (2014): Fact, Fiction and Momentum Investing. In The Journal of Portfolio Management Special 40th Anniversary, 2014, Issue 40 (5), pp. 75-92.

Auquan (Ed.) (2017): Mean Reversion: Simple Trading Strategies Part 1. Updated on 30/08/2017. Available online at https://medium.com/auquan/mean-reversionsimple-trading-strategies-part-1-a18a87c1196a, checked on 15/11/2020.

BaFin - Bundesanstalt für Finanzdienstleistungsaufsicht (Ed.) (2019): Frequently asked questions (FAQs) relating to algorithmic trading and high-frequency trading (Update: 17 July 2019). Available online at https://www.bafin.de/SharedDocs/Downloads/DE/FAQ/dl_faq_hft.html, checked on 15/11/2020.

Bank for International Settlements (Ed.) (2017): Foreign exchange liquidity in the Americas. (Report submitted by a study group established by the BIS CCA Consultative Group of Directors of Operations (CGDO) and chaired by Susan McLaughlin, Federal Reseve Bank of New York - BIS papers, no 90). Basel, 2017.

Barber, B. M.; Lee, Y.-T.; Liu, Y.-J.; Odean, T. (2004): Do Individual Day Traders Make Money? Evidence from Taiwan. Available online at https://www.researchgate.net/publication/238220682, checked on 15/11/2020.

Barber, B. M.; Lee, Y.-T.; Liu, Y.-J.; Odean, T. (2011, revised in 2013): The cross-section of speculator skill: Evidence from day trading. In Journal of Financial Markets, 2014 ,Vol. 18, pp. 1-24.

Barber, B. M.; Lee, Y.-T.; Liu, Y.-J.; Odean, T.; Zhang, K. (2017): Do Day Traders Rationally Learn About Their Ability? Available online at https://faculty.haas.berkeley.edu/odean/papers/Day\%20Traders/Day\%20Trading \%20and\%20Learning\%20110217.pdf, checked on 15/11/2020.

Basdekidou, V. A. (2017): The Momentum \& Trend-Reversal as Temporal Market Anomalies. In International Journal of Economics and Finance, 2017, Vol.9, No. 5 , p. 1.

Baz, J.; Granger, N.; Harvey, C. R.; Le Roux, N.; Rattray, S. (2015): Dissecting Investment Strategies in the Cross Section and Time Series. Available online at https://papers.ssrn.com/sol3/papers.cfm?abstract_id=2695101, checked on $15 / 11 / 2020$.

Bessembinder, H.; Venkataraman, K. (2009): Bid-Ask Spreads: Measuring Trade Execution Costs in Financial Markets. Available online at https://www.researchgate.net/publication/254354745_Bid- 
Ask_Spreads_Measuring_Trade_Execution_Costs_in_Financial_Markets, checked on 15/11/2020.

Bigiotti A., Navarra A. (2019): Optimizing Automated Trading Systems. In: Antipova T., Rocha A. (eds) Digital Science. Advances in Intelligent Systems and Computing, Vol 850, pp. 254-261, 2018.

Binance Academy (Ed.) (n.d.): Colocation. Available online at https://academy.binance.com/en/glossary/colocation, checked on 15/11/2020.

Boehmer, E.; Fong, K.; Wu, J. (2015): International Evidence on Algorithmic Trading. Available online at https://c.mq15.com/forextsd/forum/209/International\%20Evidence\%20on\%20Al gorithmic\%20Trading.pdf, checked on 15/11/2020.

Boehmer, E.; Fong, K.; Wu, J. (2019): Algorithmic Trading and Market Quality: International Evidence. Available online at http://www.depts.ttu.edu/rawlsbusiness/about/finance/researchseminar/documents/AT_Sep2019_.pdf, checked on 15/11/2020.

Boehmer, E.; Li, D.; Saar, G. (2018): The Competitive Landscape of High-Frequency Trading Firms. In The Review of Financial Studies, 2018, Vol. 31, No. 6, pp. 2227-2276.

Brenøe, M. (2018): Applying Artificial Intelligence on Momentum. An empirical study testing whether machine learning can exploit time-series patterns to generate abnormal profits. Master Thesis, Copenhagen, 2018. Available online at https://research.cbs.dk/en/studentProjects/applying-machine-learning-onmomentum-an-empirical-study-testing-, checked on 15/11/2020.

Brogaard, J.; Carrion, A.; Moyaert, T.; Riordan, R.; Shkilko, A.; and Sokolov, K. (2018): High frequency trading and extreme price movements. In Journal of Financial Economics, 2018, Vol. 128, No. 2, pp. 253-265.

Broussard, J. P.; Nikiforov, A.; Osmekhin, S. (2020): Algorithmic trading and market quality. Available online at https://ssrn.com/abstract $=3673881$, checked on $15 / 11 / 2020$.

Brunner, A.; Abderrahmane, N.; Muralidharan, A.; Halfpap, P.; Süme, O.; Zimprich, S. (2017): Trade Finance Disrupted: A Blockchain Use Case. In THE CAPCO INSTITUTE JOURNAL OF FINANCIAL TRANSFORMATION, 2017, No 45.

Charles, D. (2018): A Practical Introduction to Day Trading. Available online at https://www.cambridgescholars.com/download/sample/64855, checked on $15 / 11 / 2020$.

Chen, J. (2019): Day Trader. Updated on 16/08/2019. Available online at https://www.investopedia.com/terms/d/daytrader.asp, checked on 15/11/2020.

Chen, J. (2020a): Contract for Differences (CFD). Updated on 12/01/2020. Available online at https://www.investopedia.com/terms/c/contractfordifferences.asp, checked on $15 / 11 / 2020$.

Chen, J. (2020b): Options. Updated on 19/02/2020. Available online at https://www.investopedia.com/terms/o/option.asp, checked on 15/11/2020.

Christensen, H.; Godsill, S.; Turner, R. E. (2020): Hidden Markov Models Applied To Intraday Momentum Trading With Side Information. Available online at http://arxiv.org/pdf/2006.08307v1, checked on 15/11/2020. 
Chui, M.; Manyika, J.; Miremadi, M. (2016): Where machines could replace humansand where they can't (yet). Available online at https://www.mckinsey.com/business-functions/mckinsey-digital/ourinsights/where-machines-could-replace-humans-and-where-they-cant-yet, updated on 08/07/2016, checked on 15/11/2020.

Chung, J. M.; Choe, H.; Kho, B.-C. (2008): The Impact of Day-Trading on Volatility and Liquidity. In Asia-Pacific Journal of Financial Studies, 2008, Vol. 38, No. 2, pp 237-275.

Combley, R.: (2011): Cambridge Business English Dictionary. 2011. Available online at https://dictionary.cambridge.org/dictionary/english/.

Corporate Finance Institute (Ed.) (n.d.): Noise Trader. Available online at https://corporatefinanceinstitute.com/resources/knowledge/tradinginvesting/noise-trader/, checked on 15/11/2020.

Corporate Finance Institute (Ed.) (n.d.): Spoofing. Available online at https://corporatefinanceinstitute.com/resources/knowledge/tradinginvesting/spoofing/, checked on 15/11/2020.

Daly, K. J. (2011): An Overview of the Determinants of Financial Volatility: An Explanation of Measuring Techniques. In Modern Applied Science, 2011, Vol. 5, No. 5, pp. 46-63.

Daniel, K.; Moskowitz, T. J. (2016): Momentum crashes. In Journal of Financial Economics, 2016, Vol. 122, No. 2, pp. 221-247.

Degirmenci, A. (2014): Introduction to Hidden Markov Models. Available online at https://scholar.harvard.edu/files/adegirmenci/files/hmm_adegirmenci_2014.pdf, checked on 15/11/2020.

Deutsche Bundesbank (Ed.) (2016): Significance and impact of high-frequency trading in the German capital market. Available online at https://www.bundesbank.de/resource/blob/707606/2231b11bf81f848041be6341 195e214b/mL/2016-10-high-frequency-trading-data.pdf, checked on 15/11/2020.

EDUCBA (Ed.) (n.d.): Learning Algorithms. Available online at https://www.educba.com/learning-algorithms/, checked on 15/11/2020.

Fama, E. (1970): Efficient Capital Markets: A Review of Theory and Empirical Work. In Journal of Finance, 1970, Vol. 25, No. 2, pp. 383-417.

FIA (Ed.) (2017): What is a liquidity provider? Updated on 03/03/2017. Available online at https://www.fia.org/resources/what-liquidity-provider, checked on 15/11/2020.

Forex Live (Ed.) (2019): The science of day trading. Updated on 05/06/2019. Available online at https://www.forexlive.com/Education/!/the-science-of-day-trading20190605\#: :text=Day\%20or\%20intraday\%20trading\%20is,the\%20end\%20of $\% 20$ the\%20day, checked on 15/11/2020.

Forex Training Group (Ed.) (n.d.): The Contrarian Trading Approach - Betting Against the Masses. Available online at https://forextraininggroup.com/contrariantrading-approach-betting-masses/, checked on 15/11/2020.

Fränkle, J. (2010): Theoretical and Practical Aspects of Algorithmic Trading. Diss., Karlsruhe, 2010. Available online at https://publikationen.bibliothek.kit.edu/1000021543. 
Fukuma, N.; Kadogawa, Y. (2020): An Overview of Algorithmic Trading in Foreign Exchange Markets and Its Impacts on Market Liquidity. In Bank of Japan Review, 2020.

Gamzo, R. (2013): Algorithmic Trading, Market Efficiency and the Momentum Effect. Master Thesis, Johannesburg, 2013. Available online at http://wiredspace.wits.ac.za/jspui/bitstream/10539/13929/1/Rafael\%20Gamzo.\% 20323979.\%20Research\%20Report.\%20Algorithmic\%20Trading,\%20Market\% 20Efficiency $\% 20$ and $\% 20$ the $\% 20$ Momentum $\% 20$ Effect.pdf, checked on $15 / 11 / 2020$.

Gamzo, R. (2017): Algorithmic Trading, Market Quality and Information: a Dual-Process Account. Diss., Johannesburg, 2017. Available online at http://mobile.wiredspace.wits.ac.za/bitstream/handle/10539/26313/(Rafael\%20G amzo\%20PhD\%20Thesis)\%20Algorithmic\%20Trading\%20Market\%20Quality $\% 20$ and $\% 20$ Information\%20A\%20Dual\%20Process\%20Account.pdf?isAllowed =y\&sequence=1, checked on 15/11/2020.

Goldenstein, J.; Hunoldt, M.; Walgenbach, P. (2018): Wissenschaftliche(s) Arbeiten in den Wirtschaftswissenschaften. Wiesbaden, 2018.

Golub, A.; Glattfelder, J. B.; Olsen, R. B. (2017): The Alpha Engine: Designing an Automated Trading Algorithm. Available online at https://papers.ssrn.com/sol3/papers.cfm?abstract_id=2951348, checked on $15 / 11 / 2020$.

Gomber, P.; Arndt, B.; Lutat, M.; Uhle, T. (2011): High Frequency Trading. Available online at https://papers.ssrn.com/sol3/papers.cfm?abstract_id=1858626, checked on $15 / 11 / 2020$.

Gomber, P.; Zimmermann, K. (2018): Algorithmic Trading in Practice in The Oxford Handbook of Computational Economics and Finance. New York, 2018.

Gomolka, J.: Algorithmic Trading (2011): Analyse von computergesteuerten Prozessen im Wertpapierhandel unter Verwendung der Multifaktorenregression. Diss., Potsdam, 2011. Available online at https://d-nb.info/1014245400/34, checked on $15 / 11 / 2020$.

Grimm, R.; Delfmann, P. (2017): Digitale Kommunikation. Sprache, Protokolle und Datenformate in offenen Netzen. Kapitel 2: Algorithmen. 2., revidierte und erweiterte Auflage: De Gruyter Oldenbourg (De Gruyter Studium). Germany, 2020.

Gsell, M. (2006): Is Algorithmic Trading distinctively different? Assessing its behaviour in comparison to informed, momentum and noise traders. Available online at http://ssrn.com/abstract=1142738, checked on 15/11/2020.

Harvey, C. R. (2018): Mean reversion. Available online at https://www.nasdaq.com/glossary/m/mean-reversion, checked on 15/11/2020.

Hasbrouck, J.; Saar, G. (2010, last revised 2013): Low-latency trading. In Johnson School Research Paper Series No. 35-2010, AFA 2012 Chicago Meetings Paper.

Heiniger, F. (2015): Die Arbitrage Pricing Theory. Updated on 27/01/2015. Available online at https://www.fuw.ch/article/die-arbitrage-pricing-theory/, checked on $15 / 11 / 2020$. 
Heldens, J. (2017): Intraday Price Reversals and Momentum: Evidence from the NYSE. Available online at http://arno.uvt.nl/show.cgi?fid=144554, checked on $15 / 11 / 2020$.

Hendershott, T.; Jones, C. M.; Menkveld, A. J. (2011a): Does Algorithmic Trading Improve Liquidity? In The Journal of Finance, 2011, Vol. 66, No. 1.

Hendershott, T.; Riordan, R. (2011b): Algorithmic Trading and Information. Available online at http://faculty.haas.berkeley.edu/hender/ATInformation.pdf, checked on $15 / 11 / 2020$.

Hendershott, T.; Riordan, R. (2013): Algorithmic Trading and the Market for Liquidity. In Journal of Financial and Quantitative Analysis, 2013 Vol. 48, No. 4, pp. 10011024.

Herberger, T. A.; Horn, M.; Oehler, A. (2020): Are intraday reversal and momentum trading strategies feasible? An analysis for German blue chip stocks. In Financial Markets and Portfolio Management, 2020, Vol. 34, No. 2 pp. 179-197.

Hong, H.; Stein, J. C. (1999): A Unified Theory of Underreaction, Momentum Trading and Overreaction in Asset Markets. In Journal of Finance, 1999, Vol. 54, No. 6, pp. 2143-2184.

Jordan, D. J.; Diltz, J. D. (2003): The Profitability of Day Traders. In Financial Analysts Journal, 2003, Vol. 59, No. 6, pp. 85-94.

Kersch, M. (2014): Evaluation von Trading-Algorithmen unter realen Marktbedingungen. Ansätze zur praktischen Anwendbarkeit, Anforderungen, Implementierung. Diss., Saarbrücken, 2014. Available online at https://publikationen.sulb.unisaarland.de/bitstream/20.500.11880/23447/1/Diss_mkPublication.pdf.

Kervel, V. van; Menkveld, A. J. (2019): High-frequency trading around large institutional orders. In The Journal of Finance, 2019, Vol. 74 (3), pp. 1091-1137.

Kirilenko, A.; Kyle, A. S.; Samadi, M.; Tuzun, T. (2017): The Flash Crash: HighFrequency Trading in an Electronic Market. In The Journal of Finance, 2017, Vol. 72, No. 3, pp. 967-998.

Kisman, Z.; Restiyanita, S. M. (2015): The Validity of Capital Asset Pricing Model (CAPM) and Arbitrage Pricing Theory (APT) in Predicting the Return of Stocks in Indonesia Stock Exchange 2008-2010. In American Journal of Economics, Finance and Management, 2015, Vol. 1, No. 3, pp. 184-189.

Lee, A. D.; Choy, S. (2014): Contracts for dummies? The performance of investors in contracts for difference. In Account Finance, 2014, Vol. 54, No. 3, pp. 965-997.

Lee, D.; Leung, T. (2020): On the Efficacy of Optimized Exit Rule for Mean Reversion Trading. Available online at https://ssrn.com/abstract $=3626471$, checked on $15 / 11 / 2020$.

Lee, E.; Park, K. S.; Jang, H. (2007): How Profitable is Day-trading?: A Study on Daytrading in Korean Stock Market. In Asia-Pacific Journal of Financial Studies, 2007, Vol. 36, No. 3, pp351-385.

Leseur, M. (2016): Analysis of the causes of the Momentum effect and their implications for the Efficient Market Hypothesis. Masters Thesis, Liege. Available online at https://matheo.uliege.be/bitstream/2268.2/1850/1/Final\%20Thesis\%20ML.pdf, checked on 15/11/2020. 
Leung, T.; Li, J.; Li, X.; Wang, Z. (2016): Speculative Futures Trading under Mean Reversion. In Asia-Pacific Financial Markets, 2016, Vol. 23, No. 4, pp. 281-304.

Lin, T. C.W. (2017): The New Market Manipulation. In Emory Law Journal, 2017, Vol. 66, pp. 1253.

Marling, H.; Emanuelsson, S. (2012): The Markowitz Portfolio Theory. Available online at http://www.smallake.kr/wpcontent/uploads/2016/04/HannesMarling_SaraEmanuelsson_MPT.pdf, checked on $15 / 11 / 2020$.

Marr, B. (2018): Artificial Intelligence: What's The Difference Between Deep Learning And Reinforcement Learning? Updated on 22/10/2018. Available online at https://www.forbes.com/sites/bernardmarr/2018/10/22/artificial-intelligencewhats-the-difference-between-deep-learning-and-reinforcementlearning/?sh=6f4666bc271e, checked on 15/11/2020.

Marwah, N. (2020): 5 Momentum Picks Screened on Driehaus Strategy. Updated on 22/09/2020. Available online at https://www.nasdaq.com/articles/5-momentumpicks-screened-on-driehaus-strategy-2020-09-22, checked on 15/11/2020.

McIntosh, C. (2013): Cambridge Advanced Learner's Dictionary \& Thesaurus. Fourth edition, 2013.

Moskowitz, T. (2010): Explanations for the Momentum Premium. Available online at https://www.aqr.com/Insights/Research/White-Papers/Explanations-for-theMomentum-Premium, checked on 15/11/2020.

Moles, P.; Terry, N. (1997): The Handbook of International Financial Terms, Oxford, 1997.

Mukerji, P.; Chung, C.; Walsh, T.; Xiong, B. (2019): The Impact of Algorithmic Trading in a Simulated Asset Market. In Journal of Risk and Financial Management, 2019, Vol. 12, No. 2, p. 68.

Plastun, A.; Strochenko, N.; Zhmaylova, O.; Sliusareva, L.; Bashlay, S. (2020): Momentum and contrarian effects in the Ukrainian stock market: case of daily overreactions. In Investment Management and Financial Innovations, 2020, Vol. 17, No. 1, pp. 24-34.

Prabhakaran, S. (n.d.): Augmented Dickey Fuller Test (ADF Test) - Must Read Guide. Available online at: https://www.machinelearningplus.com/timeseries/augmented-dickey-fuller-test/, checked on 20/11/2020.

Rickenberg, L. (2020): Risk-Managed Momentum Strategies. Available online at https://ssrn.com/abstract=3448995, checked on 15/11/2020.

Roşu, I. (2019): Fast and slow informed trading. In Journal of Financial Markets, 2019, Vol. 43, pp. 1-30.

Schulmeister, S. (2009): Profitability of technical stock trading: Has it moved from daily to intraday data? In Review of Financial Economics, 2009, Vol. 18, No. 4, pp. 190-201.

Seth, S. (2019): Top Day Trading Instruments. Updated on 25/06/2019. Available online at https://www.investopedia.com/articles/active-trading/030415/top-day-tradinginstruments.asp, checked on 15/11/2020.

Seth, S. (2020): The World of High-Frequency Algorithmic Trading. Updated on $30 / 04 / 2020$.

Available online 
https://www.investopedia.com/articles/investing/091615/world-high-frequencyalgorithmic-trading.asp, checked on 15/11/2020.

Souza, T.; Kolchyna, O.; Treleaven, P. C.; Aste, T. (2015): Twitter Sentiment Analysis Applied to Finance: A Case Study in the Retail Industry. Available online at http://arxiv.org/pdf/1507.00784v3.

Spierdijk, L.; Bikker, J. (2012): Mean Reversion in Stock Prices: Implications for LongTerm Investors. Available online at https://www.dnb.nl/binaries/Working\%20Paper\%20343_tcm46-271856.pdf, checked on 15/11/2020.

Stenfors, A.; Susai, M. (2018): Spoofing and Pinging in Foreign Exchange Markets. Available online at https://papers.ssrn.com/sol3/papers.cfm?abstract_id=3276578, checked on $15 / 11 / 2020$.

Stübinger J.; Bredthauer, J. (2017): Statistical Arbitrage Pairs Trading with Highfrequency Data. In International Journal of Economics and Financial Issues, 2017, Vol 7, No. 4, pp. 650-662.

Stübinger, J.; Schneider, L. (2019): Statistical Arbitrage with Mean-Reverting Overnight Price Gaps on High-Frequency Data of the S\&P 500. In Journal of Risk and Financial Management, 2019, Vol. 12, No. 2, pp. 51-70.

The European Parliament and the Council of the European Union (Ed.) (2014): Directive 2014/65/EU of the European Parliament and of the Council of 15 May 2014 on markets in financial instruments and amending Directive 2002/92/EC and Directive 2011/61/EU. In Official Journal of the European Union, 2014.

Tian, Y. (2009): Market Liquidity Risk and Market Risk Measurement. Available online at https://papers.ssrn.com/sol3/papers.cfm?abstract_id=1576231, checked on $15 / 11 / 2020$.

Torraco, R. J. (2005): Writing Integrative Literature Reviews: Guidelines and Examples. In Human Resource Development Review, 2005, Vol. 4, No.3, pp. 356-367.

Tracy, P. (n.d.): What is Abnormal Return? Updated on 12/08/2020. Available online at https://investinganswers.com/dictionary/a/abnormal-return, checked on 15/11/2020.

Trading Investment (Ed.) (2015): Don't Confuse Statistical Arbitrage with Deterministic Arbitrage. Updated on 18/06/2015. Available online at https://tradinginvestment.weebly.com/blog/-dont-confuse-statistical-arbitragewith-deterministic-arbitrage, checked on 15/11/2020.

U.S. Securities and Exchange Commission (Ed.) (2020): Staff Report on Algorithmic Trading in U.S. Capital Markets. Available online at https://www.sec.gov/files/Algo_Trading_Report_2020.pdf, checked on $15 / 11 / 2020$.

Uzialko, A. (2019): Workplace Automation is Everywhere, and It's Not Just About Robots. Updated on 26/02/2019. Available online at https://www.businessnewsdaily.com/9835-automation-tech-workforce.html, checked on 11/15/2020.

Weisstein, E. W. (n.d.): Reversion to the Mean. Available online at https://mathworld.wolfram.com/ReversiontotheMean.html, checked on $15 / 11 / 2020$. 
Werl, P. (2014): Arbitrage Opportunities in Selected Financial Markets of East Asia. Diploma Thesis, Brno, 2014. Available online at https://is.muni.cz/th/pn16b/diploma-thesis.pdf.

Wiśniewska, M. (2014): Eurusd Intraday Price Reversal. In Folia Oeconomica Stetinensia, 2014, Vol. 14, No. 2, pp. 152-162.

Yeo, D. (2014): Ornstein-Uhlenbeck Process. Available online at https://eventuallyalmosteverywhere.wordpress.com/2014/10/11/ornsteinuhlenbeck-process/, checked on 20/11/2020.

Zhou, H. (2017): Algorithmic Trading and High Frequency Trading. Available online at https://www.pdfdrive.com/download.pdf?id=53880505\&h=2f8ad3e0834f75129 eda0a8f232d5432\&u=cache\&ext=pdf, checked on 15/11/2020.

Zhou, H.; Kalev, P. S.; Frino, A. (2020): Algorithmic trading in turbulent markets. In Pacific-Basin Finance Journal, 2020, Vol. 62. 


\section{Declaration of Honor}

I hereby declare that no part of this work has been submitted in support of another module, degree, or any other qualification at the HTWK Leipzig or any other university or institute of higher education. I confirm that the work presented has been performed and interpreted solely by me except where explicitly identified to the contrary. Any use made of the works of other authors, in any form (e.g. ideas, figures, text, tables, etc.) have been properly cited and /or acknowledged.

Leipzig, $5^{\text {th }}$ December 2020

$$
\text { 2. hater }
$$

Luisa Müller 